\title{
Drought Identification through Climatic Variables
}

\author{
Oluwarotimi Jacob Adegboye, Oluseyi Enitan Ogunsola \\ Department of Physics, University of Ibadan, Ibadan, Nigeria \\ Email: adegboye.ayanfe@gmail.com, seyiogunsola22@gmail.com
}

How to cite this paper: Adegboye, O.J. and Ogunsola, O.E. (2021) Drought Identification through Climatic Variables. Open Access Library Journal, 8: e7209.

https://doi.org/10.4236/oalib.1107209

Received: February 3, 2021

Accepted: March 27, 2021

Published: March 30, 2021

Copyright () 2021 by author(s) and Open Access Library Inc.

This work is licensed under the Creative Commons Attribution International License (CC BY 4.0).

http://creativecommons.org/licenses/by/4.0/

\begin{abstract}
Temperature and rainfall are among the climatic variables required in determining the availability of water in an environment, especially for agricultural purposes and domestic consumption by man. However, there are concerns that these variables are being affected by global warming which thus necessitates the need to study their impact on the environment such as the identification of drought. The mean monthly temperature and rainfall data utilized in this work were obtained from the Nigerian Meteorological Agency (NIMET), Lagos, Nigeria for the period 1981 to 2010, and analyzed using the descriptive statistical approach including the rainfall anomalies index. After the analysis, the results showed that a non-uniform pattern of changes in temperature was evident across the different stations considered in which the variations in the local temperature trends were not spatially uniform. Twelve of the stations (Calabar, Port-Harcourt, Owerri, Benin, Enugu, Lagos, Ondo, Ibadan, Ilorin, Maiduguri, Sokoto and Katsina) out of the 18 stations considered have their mean monthly temperature increasing, which shows that majority of these stations are experiencing warming. In essence, the rainfall anomaly index thus showed that there is an evidence of drought in some of these stations considered (Warri, Benin, Enugu, Minna, Nguru, Sokoto and Katsina). However, it is important to continually check for both temperature trends and rainfall anomalies for enhanced and good agricultural planning of a nation since it was discovered that each particular area has unique rainfall and temperature patterns which are non-consistent with each other.
\end{abstract}

\section{Subject Areas}

Atmospheric Sciences, Environmental Sciences

\section{Keywords}

Temperature, Rainfall, Drought, Warming, Anomalies Index 


\section{Introduction}

Climatic variables are the parameters such as temperature and rainfall upon which climate change variability depends on. Of recent there is a great concern over the negative impact of climate change which has strengthened the fears that environmental degradation and demographic pressures will displace millions of people in Africa, thereby creating serious social upheaval. Also scientists studying the potential impact of climate change have predicted that Africa is likely to experience higher temperatures, rising sea levels, changing rainfall patterns and increased climate variability, all of which could affect much of its population (Nebedum et al., 2016) [1]. Since the impacts of climate change are spatially heterogeneous across a range of geopolitical scales, it was believed that developing countries would be more at risk because of their reliance on climate-sensitive sectors (Godwin, 2015) [2]. Also the impact of climate change is now more pronounced worldwide with consequences of climatic hazards such as severe storms, floods, heat waves and droughts.

In essence, climate variability has been attributed to changes in rainfall patterns (Adger et al., 2003 [3]; Obot et al., 2010 [4]) as a result of the large inter-annual rainfall variability which often results in climatic and environmental hazards, there is the need to study rainfall characteristics due to the occurrence of recent socio-economic developments such as urbanization, industrialization and over-population (Joshua and Ekwe, 2013) [5].

Moreover, since the global climate has been noticed to have changed rapidly, with the global mean temperature increasing by $0.7^{\circ} \mathrm{C}$ within the last century, and the rates of change are significantly different among regions (IPPC, 2007) [6], hence, there is the need to study the impact of both the temperature and rainfall, especially in the identification of drought in our environment. Therefore, the purpose of this research is to study and analyse both temperature and rainfall, over a certain period of time in order to identify the areas prone to drought.

\section{Methodology}

The mean monthly temperature and rainfall data for the period of 30 years utilized in this work were obtained from the Nigerian Meteorological agency (NIMET). A similar approach used by Kruger and Shingle (2004) [7], including Milambo et al., (2011) [8] were used to analyze the data. The mean annual temperature was calculated from the average monthly minimum and maximum temperatures. Also, the trends were estimated by fitting linear regression lines on the monthly temperature data.

The linear trend function (Equation (1)) was applied in fitting the seasonal annual temperature at the various stations considered.

$$
f(x, t)=a x(t)+b
$$

where $x(t)$ is the seasonal/annual temperature (e.g., average, maximum or 
minimum temperature) at $t$ (months) $=1,2, \cdots, 360$ and $a$ is the linear trend (in ${ }^{\circ} \mathrm{C} /$ year).

The seasonal and annual temperature averages were calculated for each of the stations considered and their corresponding trends also determined. The seasons were defined in terms of the normal season of the region, e.g. rainy season (April to October) and dry season (November to March).

The rainfall anomaly index (Van Rooy, 1965) [9] was used to describe the rainfall variability has been used by (Tilahun, 2005) [10]. The drought index was calculated for the region using rainfall variability indices in order to establish some arbitrary values for drought identification. Also utilized were the mean rainfall for the total period considered (1981 to 2010), mean of the 10 highest values of rainfall recorded, and mean of the 10 lowest values of rainfall recorded for each of the decades within the period considered.

The annual Rainfall Anomaly Index $(R A I)$ for Positive anomalies is calculated as:

$$
R A I+v e=+3\left[\frac{R F-M_{R F}}{M_{H 10}-M_{R F}}\right]
$$

While that of negative anomalies is calculated as

$$
R A I-v e=-3\left[\frac{R F-M_{R F}}{M_{L 10}-M_{R F}}\right]
$$

where $R F$ is the actual rainfall for a given year, $M_{R F}$ is the mean rainfall for the period considered $M_{H 10}$ is the mean rainfall for 10 of the highest values of rainfall on record, and $M_{L 10}$ is the mean rainfall for 10 of the lowest values of rainfall on record the period considered.

\section{Results and Discussion}

\subsection{Trends of Annual Maximum Temperature, Minimum Temperature and Annual Mean Temperature}

Out of the 18 stations considered in this study, the mean maximum temperature in ten (10) of the stations (Calabar, Benin, Ibadan, Minna, Jos, Bauchi, Maiduguri, Kano, Sokoto and Katsina) are increasing (i.e. positively) (Figure 1). While the mean minimum temperature in eleven (11) of the stations (Enugu, Ondo, Ilorin, Minna, Jos, Bauchi, Maiduguri, Nguru, Kano, Sokoto and Katsina) are also increasing (Figure 2) in a similar manner to that of the maximum temperature. This show that the minimum temperature in majority of the stations considered is catching up with the maximum temperature (i.e. Diurnal Temperature Range (DRT) is reducing) which is responsible for global warming. However seven (7) out of the nine (9) stations in the northern part of the country are warming up seriously (Minna, Jos, Bauchi, Maiduguri, Nguru, Sokoto and Katsina). Furthermore, on a general bases, out of the 18 stations considered, 12 of the stations (Calabar, Port-Harcourt, Owerri, Benin, Enugu, Lagos, Ondo, Ibadan, Ilorin, Maiduguri, Sokoto and Katsina) which are mainly stations in the 


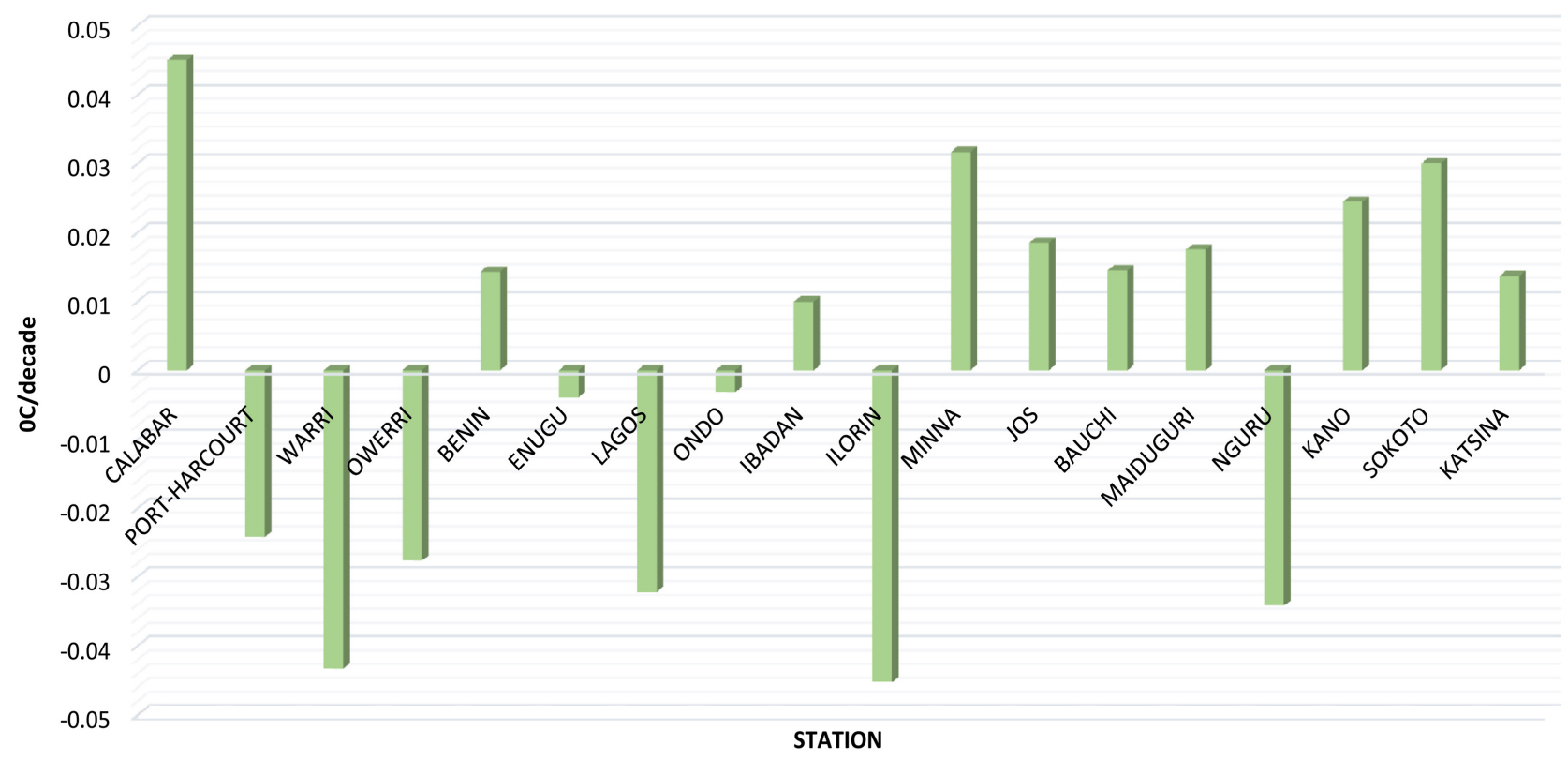

Figure 1. Mean maximum annual temperature trend for the stations considered.

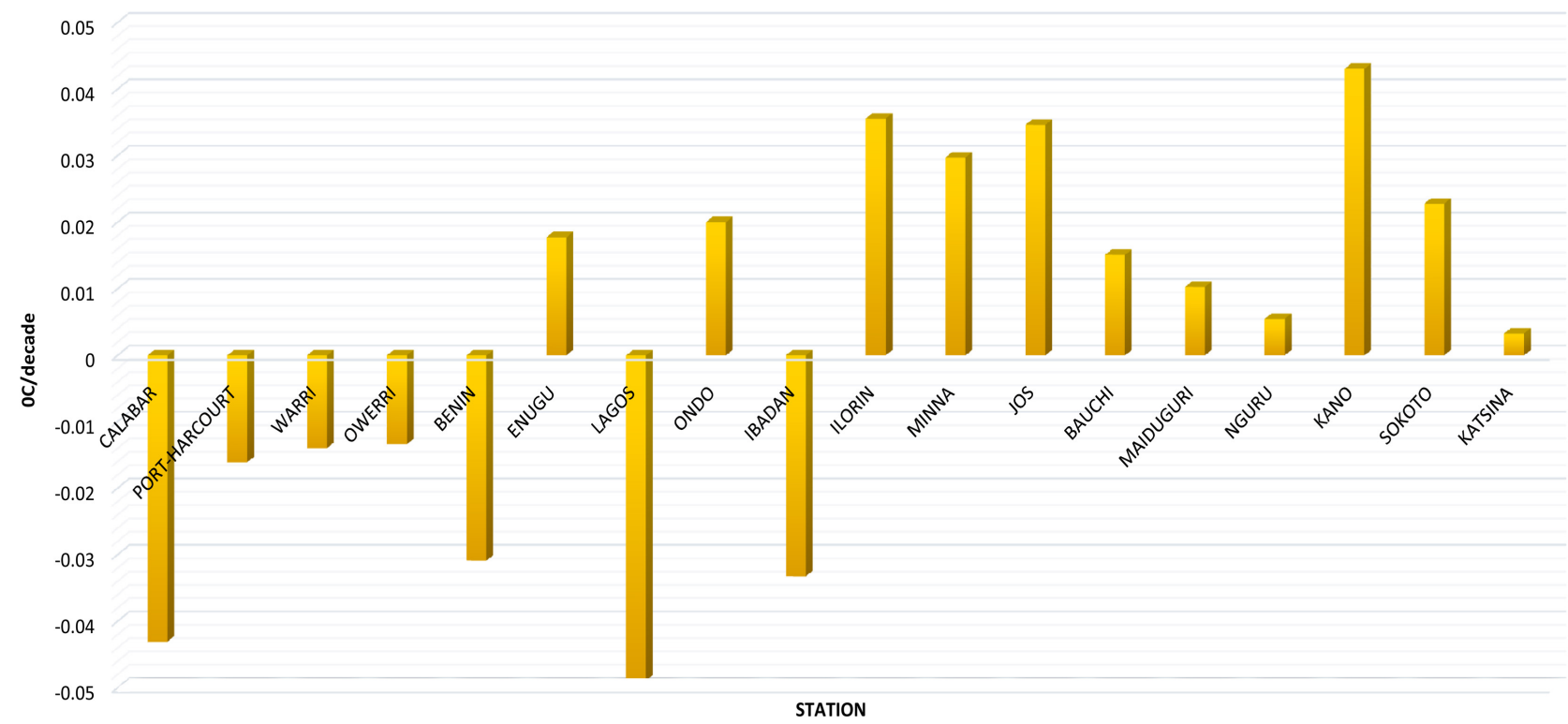

Figure 2. Mean minimum annual temperature trend for the stations considered.

southern part of the country has their annual mean temperature increasing (Figure 3), which show that majority of these locations in the country are also experiencing warming.

\subsection{Seasonal Trends}

Out of the 18 stations considered for seasonal trend, eight (8) of the stations are having values above the mean rainfall for the period of study, while the remaining nine (9) are having values below the mean rainfall for the period of study (Figure 4). 


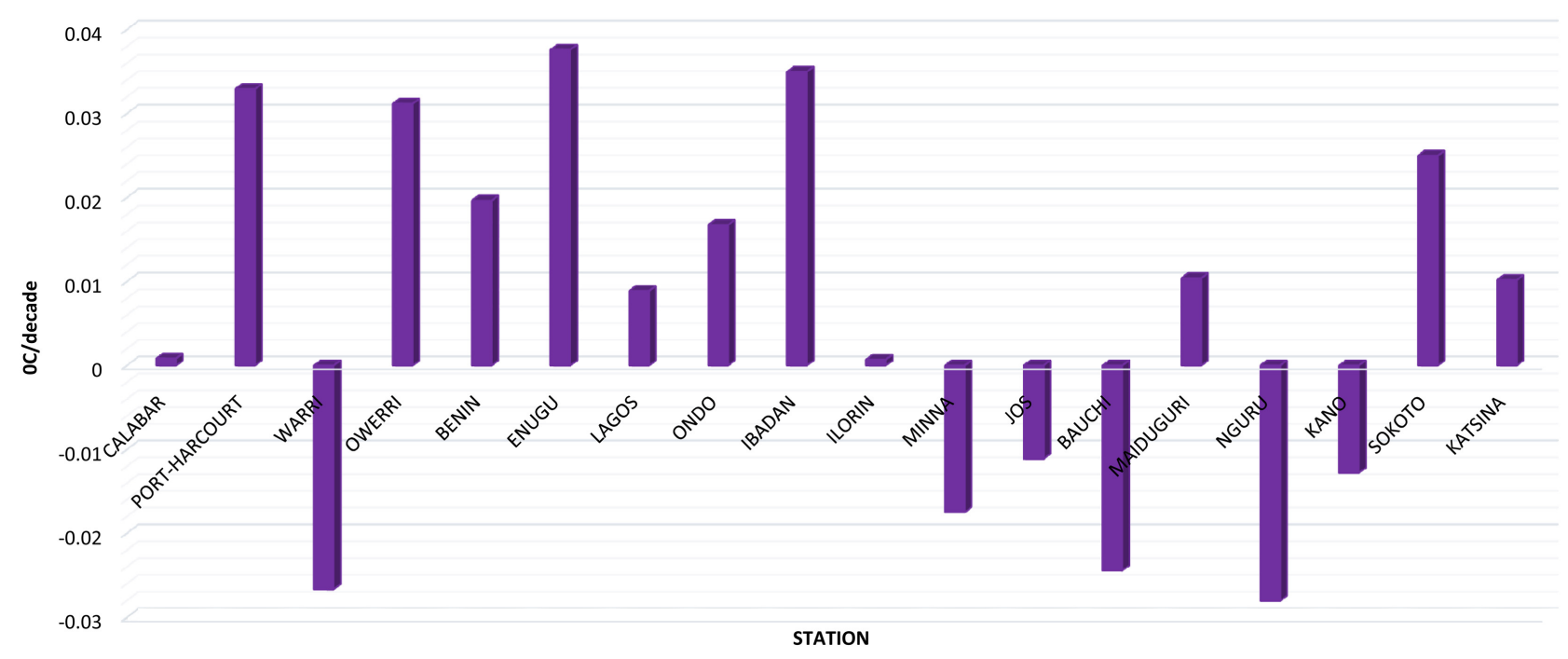

Figure 3. Mean annual temperature trend for the stations considered.

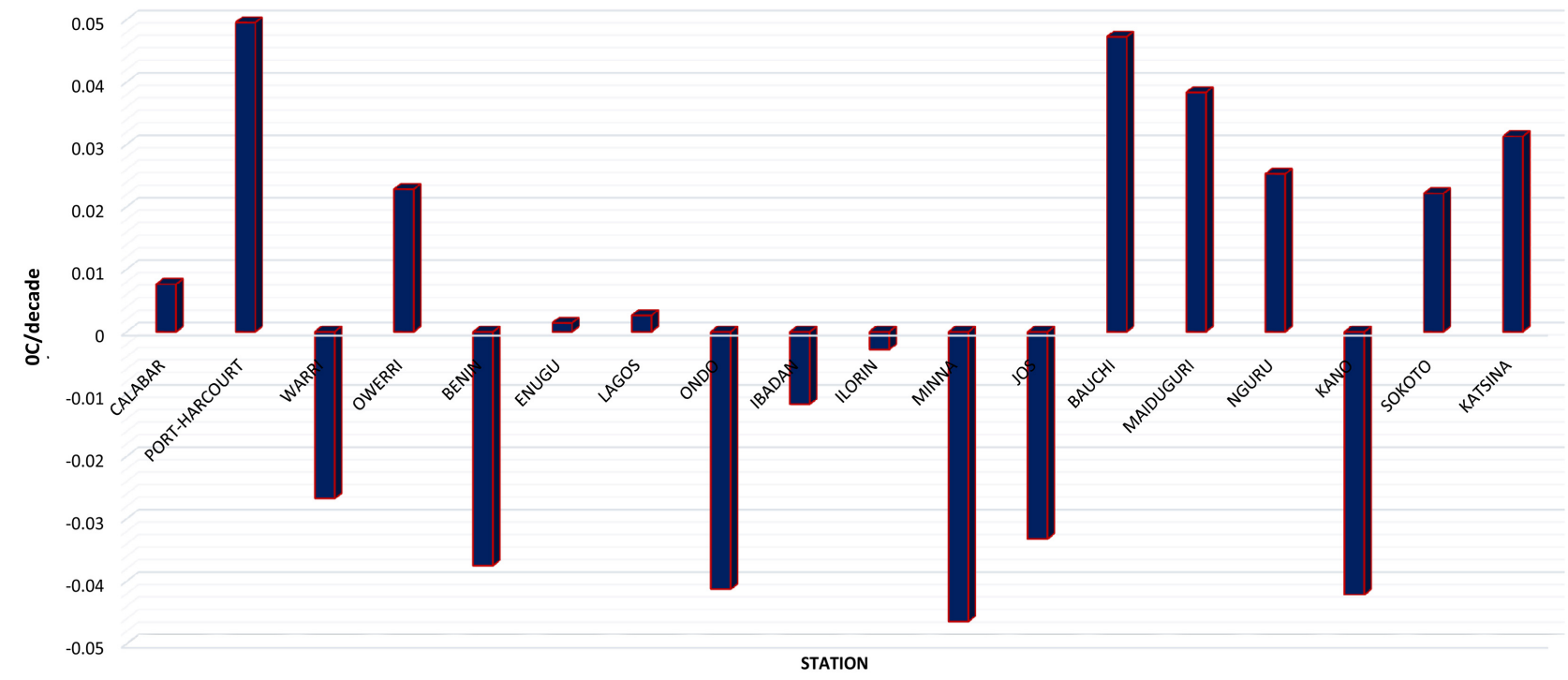

Figure 4. Mean trend for rainy season.

\subsection{Mean Monthly Temperature}

The temperature analyses for the mean monthly temperature at Calabar, Port-Harcourt and Warri. (Figure 5) showed that at Calabar, the months November and May are the months with the highest temperatures. The lowest temperatures occur in August (about $25.1^{\circ} \mathrm{C}$ ), with the average annual temperature being about $26.8^{\circ} \mathrm{C}$. Moreover the temperature analysis for the mean monthly temperature at Port-Harcourt shows that January and May are the months with the highest temperatures. The lowest temperatures occur in July and August (about $25.2^{\circ} \mathrm{C}$ ), with the average annual temperature being about $27^{\circ} \mathrm{C}$. Furthermore the temperature analysis for Warri shows that October and May are the months with the highest temperatures. The lowest temperatures occur in July and August (about $26^{\circ} \mathrm{C}$ ), with the average annual temperature 


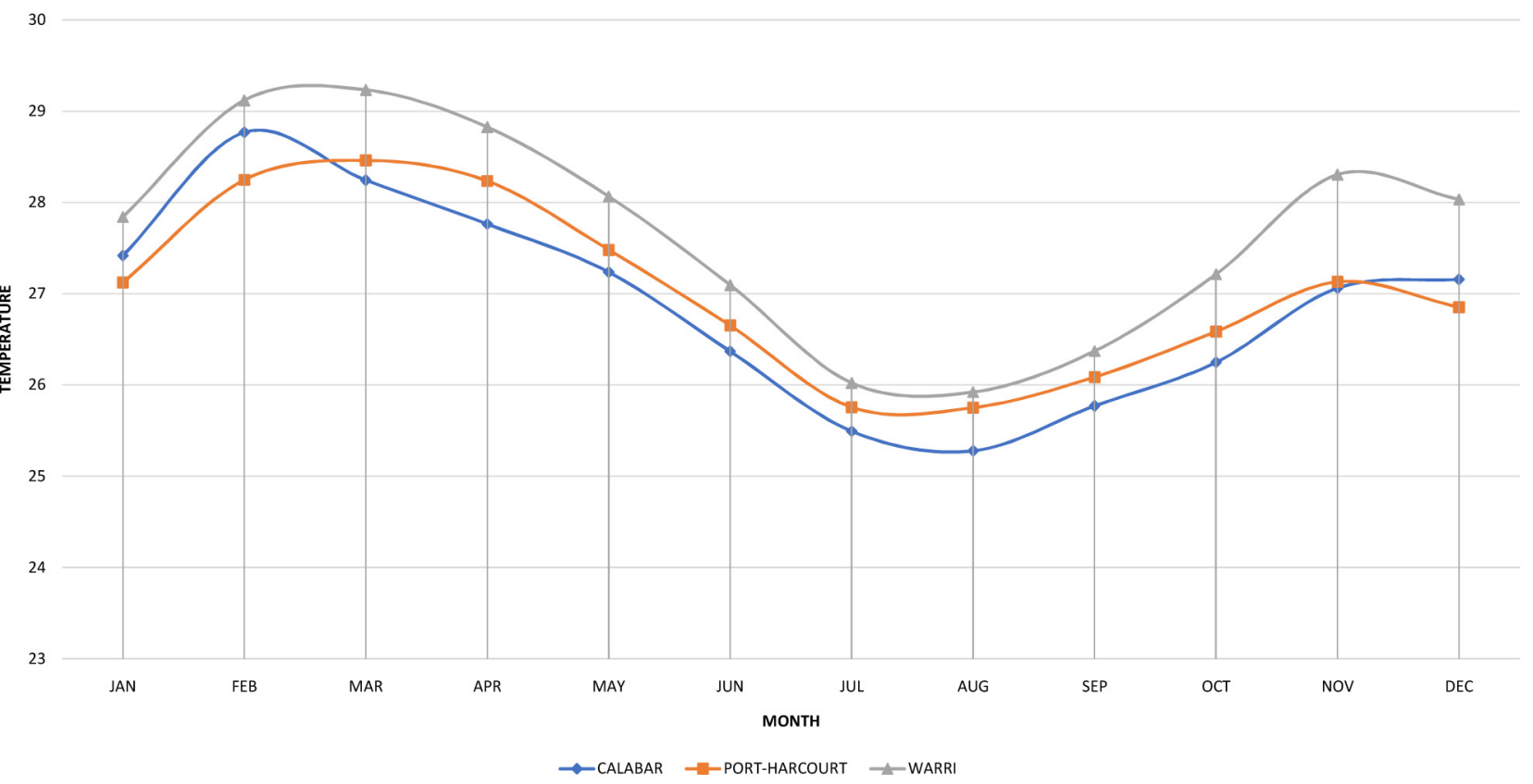

Figure 5. Mean monthly temperature for Calabar, Port-Harcourt and Warri.

being about $27.6^{\circ} \mathrm{C}$.

The temperature analysis for the mean monthly temperature at Owerri, Benin and Enugu in (Figure 6) show that November to December and February to April are the months with the highest temperatures. The lowest temperatures occur in July and August (about $26^{\circ} \mathrm{C}$ ), with the average annual temperature being about $27.8^{\circ} \mathrm{C}$. Also the temperature analysis for mean monthly temperature at Benin shows that November to May are the months with the highest temperatures. The lowest temperatures occur in August (about $25.5^{\circ} \mathrm{C}$ ), with the average annual temperature being about $27.5^{\circ} \mathrm{C}$. Furthermore the temperature analysis for mean monthly temperature at Enugu shows that January to May are the months with the highest temperatures. The lowest temperatures occur in August (about $26^{\circ} \mathrm{C}$ ), with the average annual temperature being about $27.4^{\circ} \mathrm{C}$.

The temperature analyses for the mean monthly temperature at Lagos, ondo and Ibadan in (Figure 7) show that October and May are the months with the highest temperatures. The lowest temperatures occur in July and August (about $25.5^{\circ} \mathrm{C}$ ), with the average annual temperature being about $27.3^{\circ} \mathrm{C}$. Moreover the temperature analysis for the mean monthly temperature at Ondo shows that October and April are the months with the highest temperatures. The lowest temperatures occur in August (about $24.8^{\circ} \mathrm{C}$ ), with the average annual temperature being about $26.8^{\circ} \mathrm{C}$. Likewise the temperature analysis for the mean monthly temperature at Ibadan shows that November and May are the months with the highest temperatures. The lowest temperatures occur in August (about $25^{\circ} \mathrm{C}$ ), with the average annual temperature being about $27.2^{\circ} \mathrm{C}$.

The temperature analyses for the mean monthly temperature at Ilorin, Minna and Jos in (Figure 8) showed that November and January to May are the months 


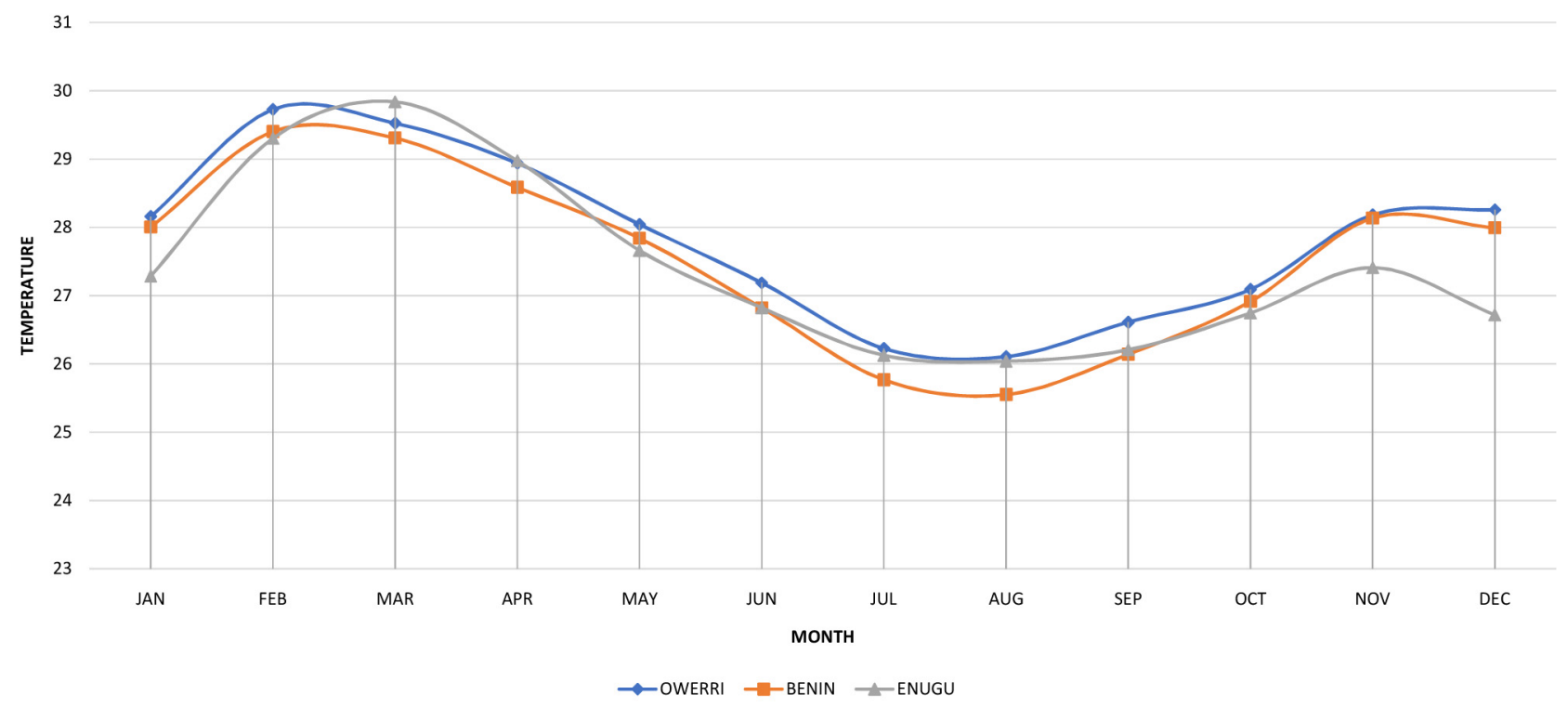

Figure 6. Mean monthly temperature for Owerri, Benin and Enugu.

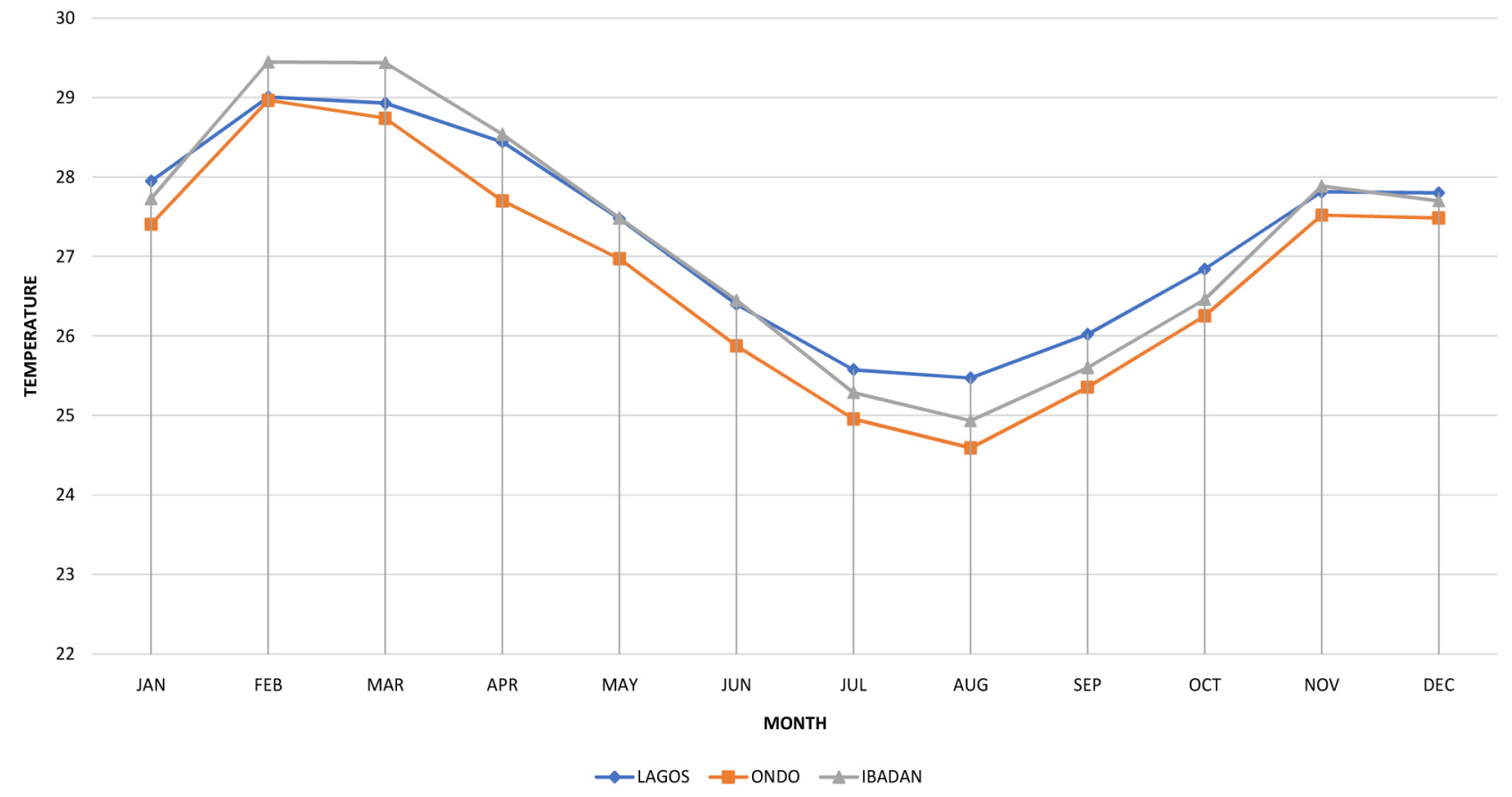

Figure 7. Mean monthly temperature for Lagos, Ondo and Ibadan.

with the highest temperatures. The lowest temperatures occur in August (about $25^{\circ} \mathrm{C}$ ), with the average annual temperature being about $27.1^{\circ} \mathrm{C}$. Moreover the temperature analysis for the mean monthly temperature at Minna shows that November to May and July are the months with the highest temperatures. The lowest temperatures occur in August (about $25^{\circ} \mathrm{C}$ ), with the average annual temperature being about $27.9^{\circ} \mathrm{C}$. Furthermore the temperature analysis for the mean monthly temperature at Jos shows that September, October and February are the months with the highest temperatures. The lowest temperatures occur in 


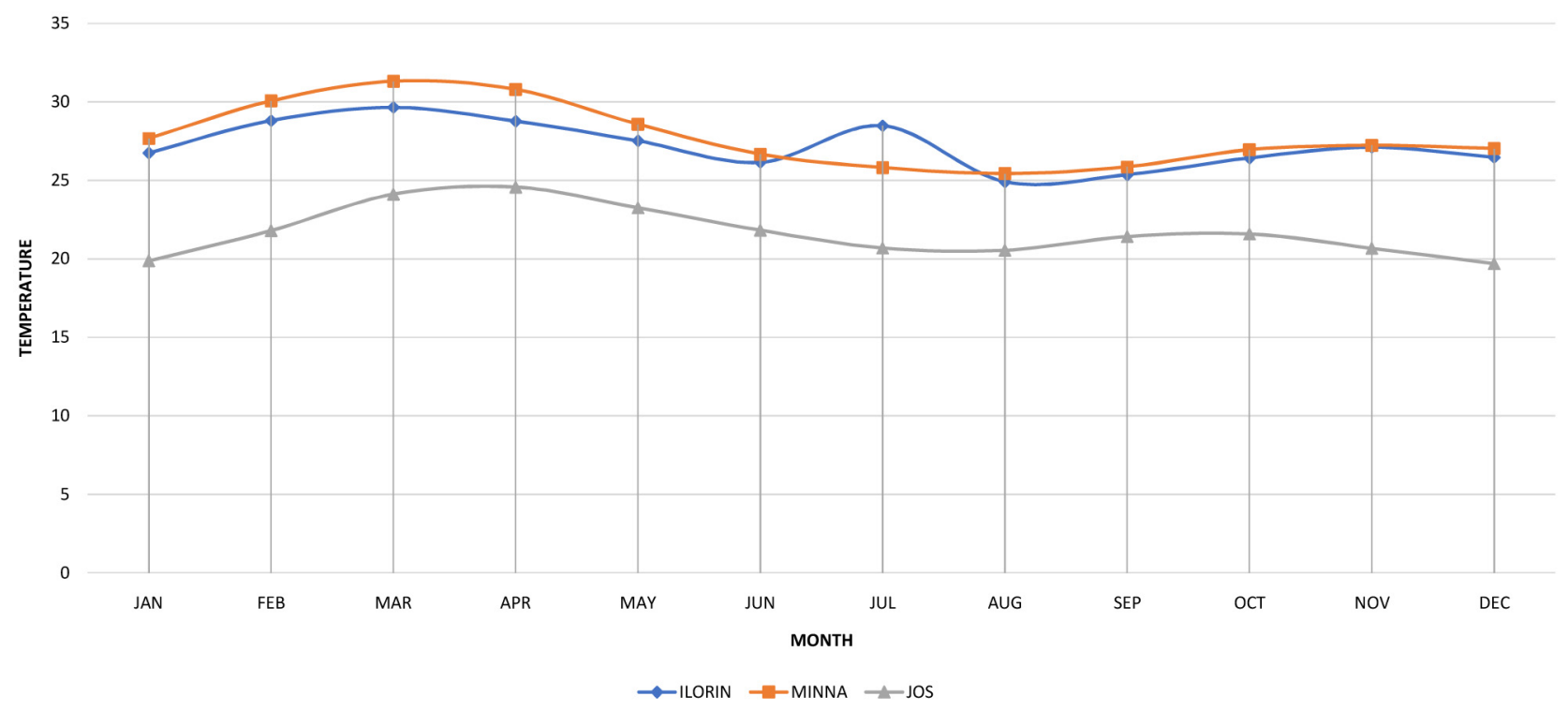

Figure 8. Mean monthly temperature for Ilorin, Minna and Jos.

August (about $20^{\circ} \mathrm{C}$ ), with the average annual temperature being about $21.6^{\circ} \mathrm{C}$.

The temperature analyses for the mean monthly temperature at Bauchi, Maiduguri and Nguru in (Figure 9) show that March to June are the months with the highest temperatures. The lowest temperatures occur in August (about $23^{\circ} \mathrm{C}$ ), with the average annual temperature being about $26.3^{\circ} \mathrm{C}$. Likewise the temperature analysis for the mean monthly temperature at Maiduguri shows that September, October and March to July are the months with the highest temperatures. The lowest temperatures occur in January (about $23^{\circ} \mathrm{C}$ ), with the average annual temperature being about $27.9^{\circ} \mathrm{C}$. Furthermore the temperature analysis for the mean monthly temperature at Nguru shows that September, October and March to July are the months with the highest temperatures. The lowest temperatures occur in August (about $23^{\circ} \mathrm{C}$ ), with the average annual temperature being about $28.2^{\circ} \mathrm{C}$.

The temperature analyses for the mean monthly temperature at Kano, Sokoto and Katsina in (Figure 10) show that March and June are the months with the highest temperatures. The lowest temperatures occur in January and December (about $22^{\circ} \mathrm{C}$ ), with the average annual temperature being about $28.7^{\circ} \mathrm{C}$. Moreover the temperature analysis for the mean monthly temperature at Sokoto shows that March and June are the months with the highest temperatures. The lowest temperatures occur in January and December (about $25^{\circ} \mathrm{C}$ ), with the average annual temperature being about $29^{\circ} \mathrm{C}$. Furthermore the temperature analysis for the mean monthly temperature at Katsina shows that October, March and July are the months with the highest temperatures. The lowest temperatures occur in January (about $21^{\circ} \mathrm{C}$ ), with the average annual temperature being about $26.8^{\circ} \mathrm{C}$.

\subsection{Rainfall Anomaly Index}

The rainfall anomalies index for Calabar in (Figure 11) show that the value 


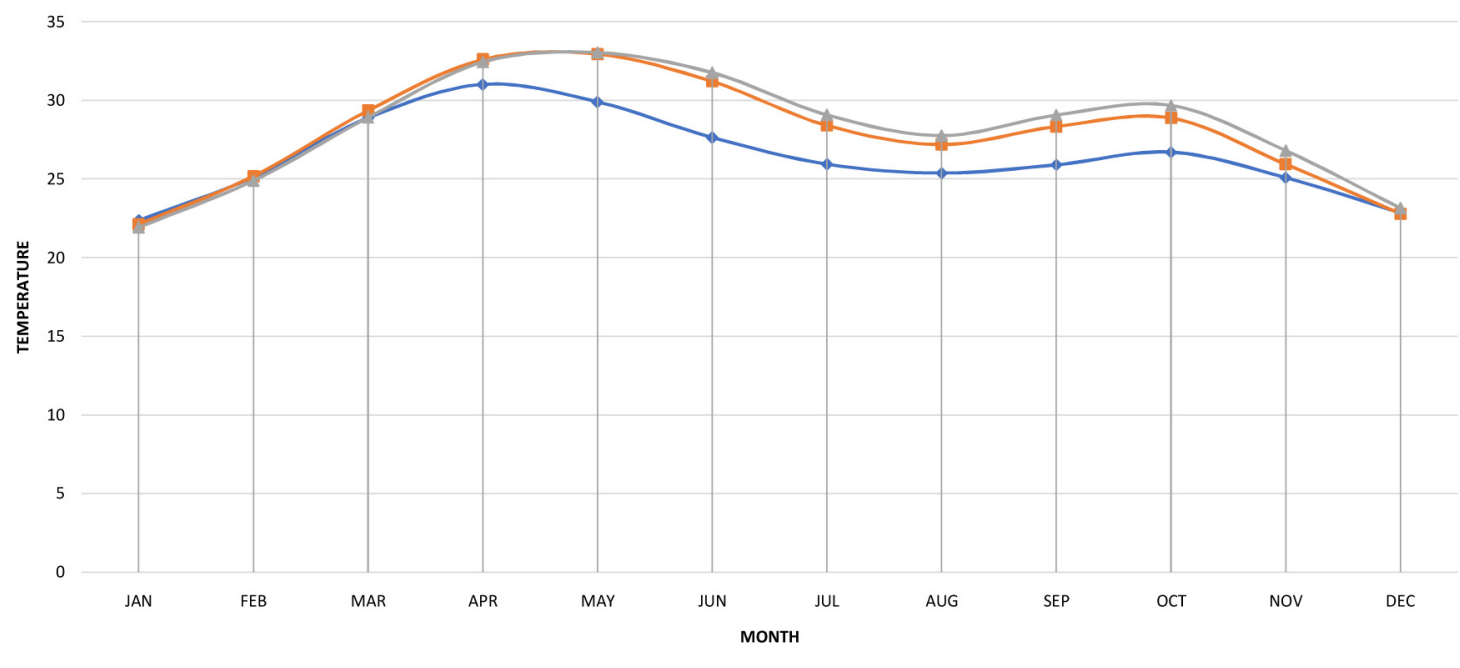

Figure 9. Mean monthly temperature for Bauchi, Maiduguri and Nguru.

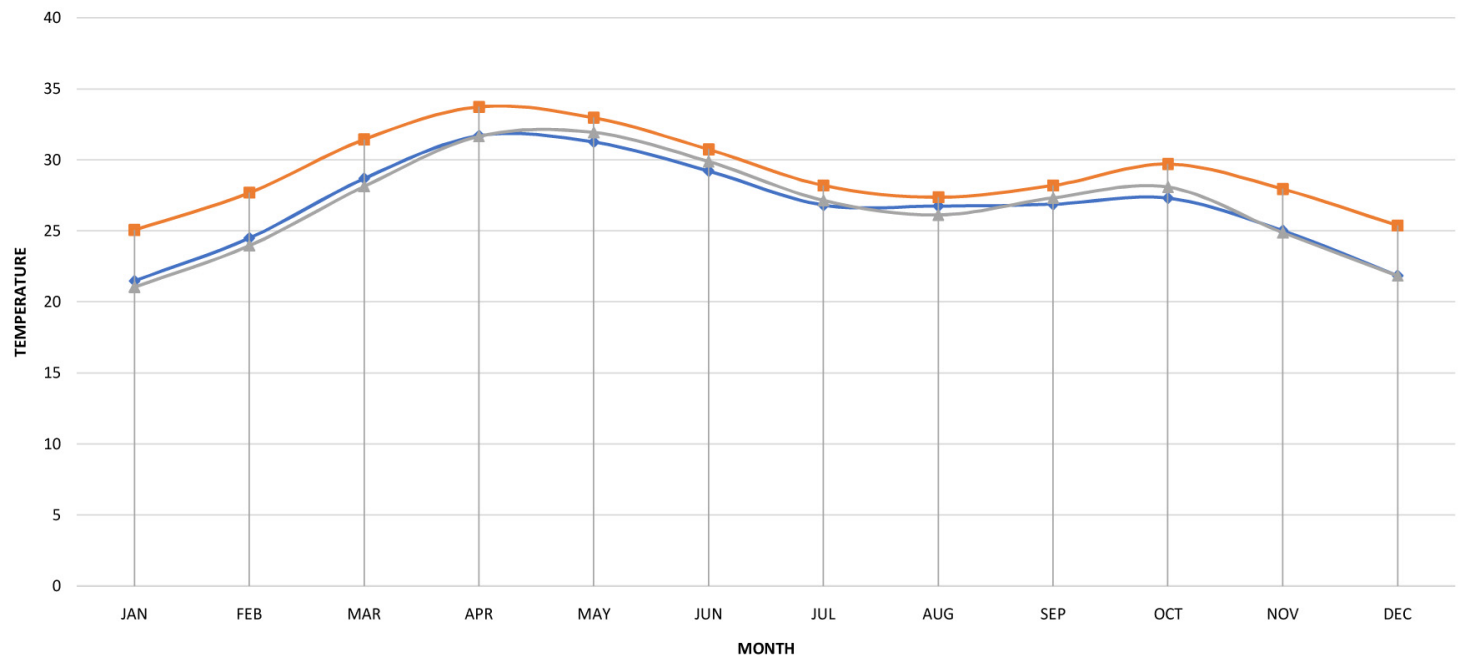

Figure 10. Mean monthly temperature for Kano, Sokoto and Katsina.

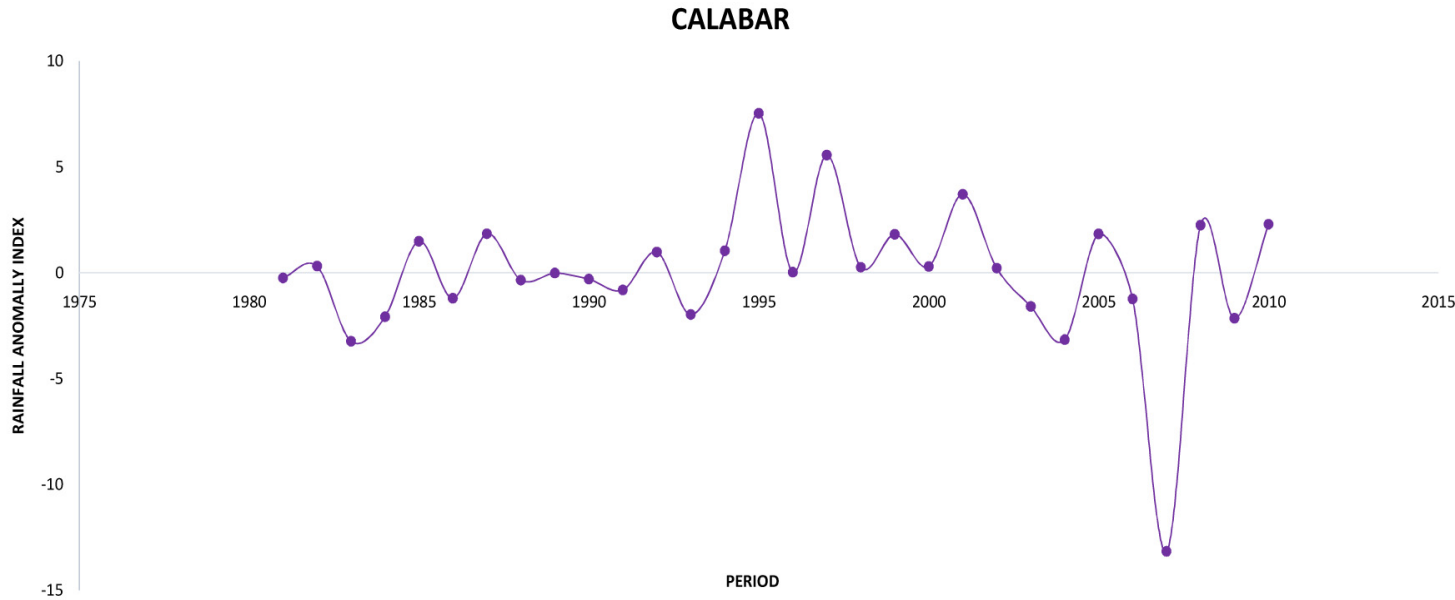

Figure 11. Rainfall anomalies index for Calabar. 
ranges from +6.9 in 1995 to -14.1 in 2007 . The rainfall was below the mean from 1980 to 1990. While it was above the long term mean from 1995 to 2009. From Equation (3), the value of rainfall anomaly index (RAI) less than -3 show that there is drought. So there is an evidence of drought in the first decade for Calabar, while there is increase in the amount of rainfall from 1995.

The rainfall anomalies index for Port-Harcourt in (Figure 12) shows that the value ranges from +8.2 in 2006 to -7.1 in 1983 . The rainfall was above the long term mean throughout the period of consideration. This shows that there is no evidence of drought for Port-Harcout.

The rainfall anomalies index for Warri in (Figure 13) show that the value is below the mean throughout the period of consideration. There is an evidence of drought for the Warri throughout the period of consideration.

PORT-HARCOURT

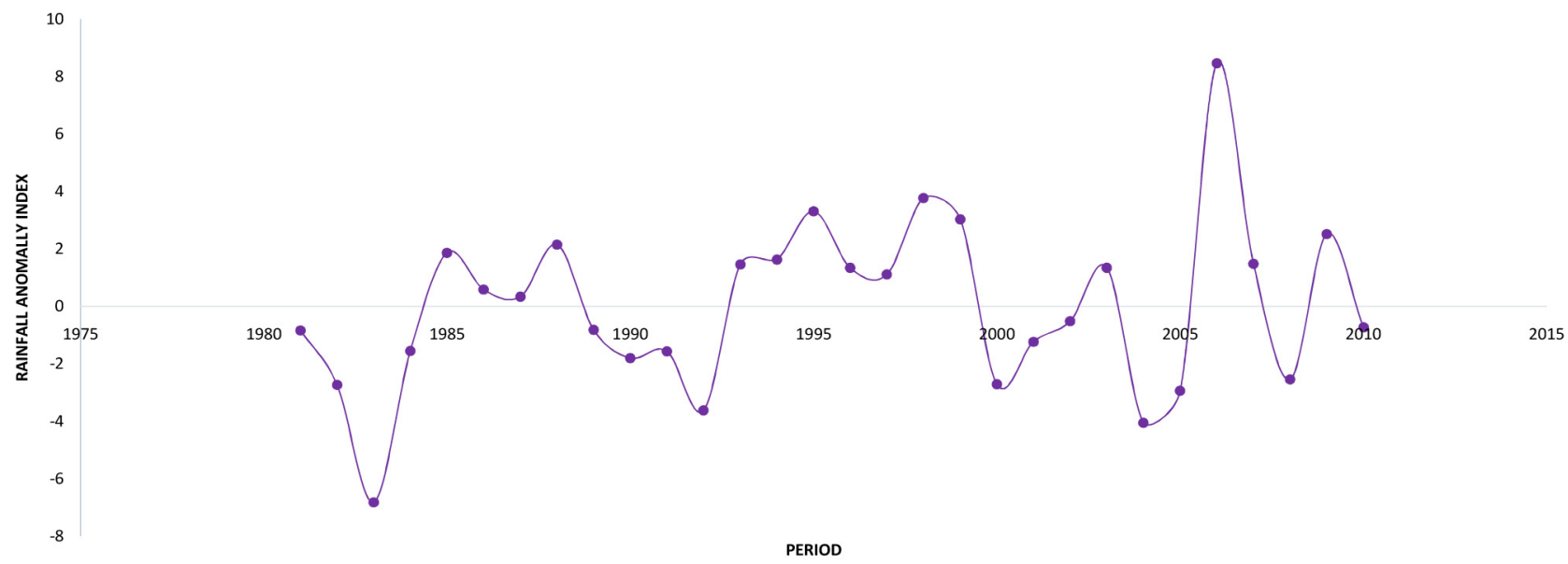

Figure 12. Rainfall anomalies index for Port-Harcourt.

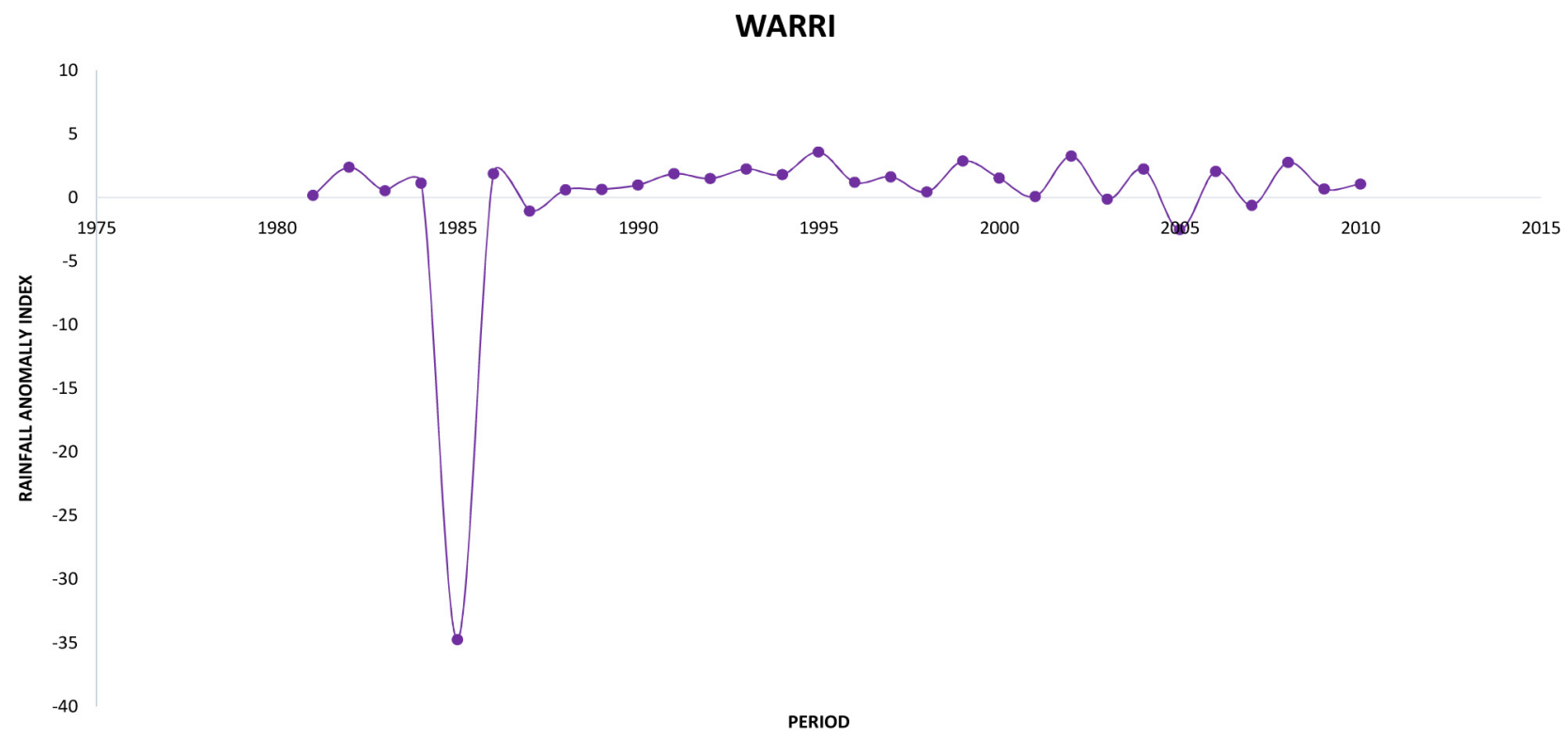

Figure 13. Rainfall anomalies index for Warri. 
The rainfall anomalies index for Owerri in (Figure 14) show that the value ranges from +4.1 in 2009 to -11.0 in 2008 . For the earlier two decades, the value below the mean and above the long term mean for the last decades. There was no evidence of drought for the last decade.

The rainfall anomalies index for Benin in (Figure 15) show that the value ranges from +4.0 in 1995 to -10.0 in 2005 . The value is below the mean throughout the period. This shows that there is an evidence of drought persistence for the station.

The rainfall anomalies index for Enugu in (Figure 16) show that the value ranges from +0.3 in 1982 to -0.15 in 1997. The value is below the mean value throughout the period of consideration. There is an evidence of drought persistence for the station.

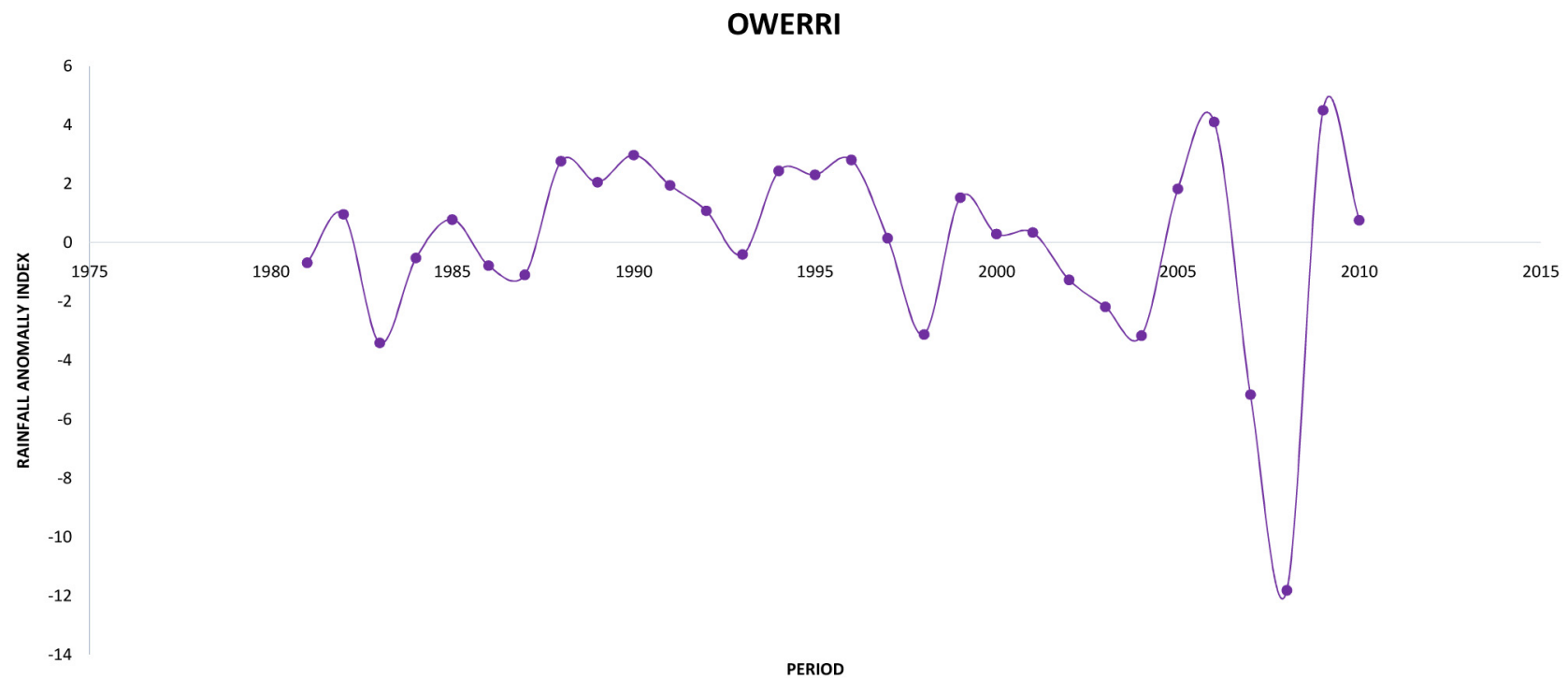

Figure 14. Rainfall anomalies index for Owerri.

\section{BENIN}

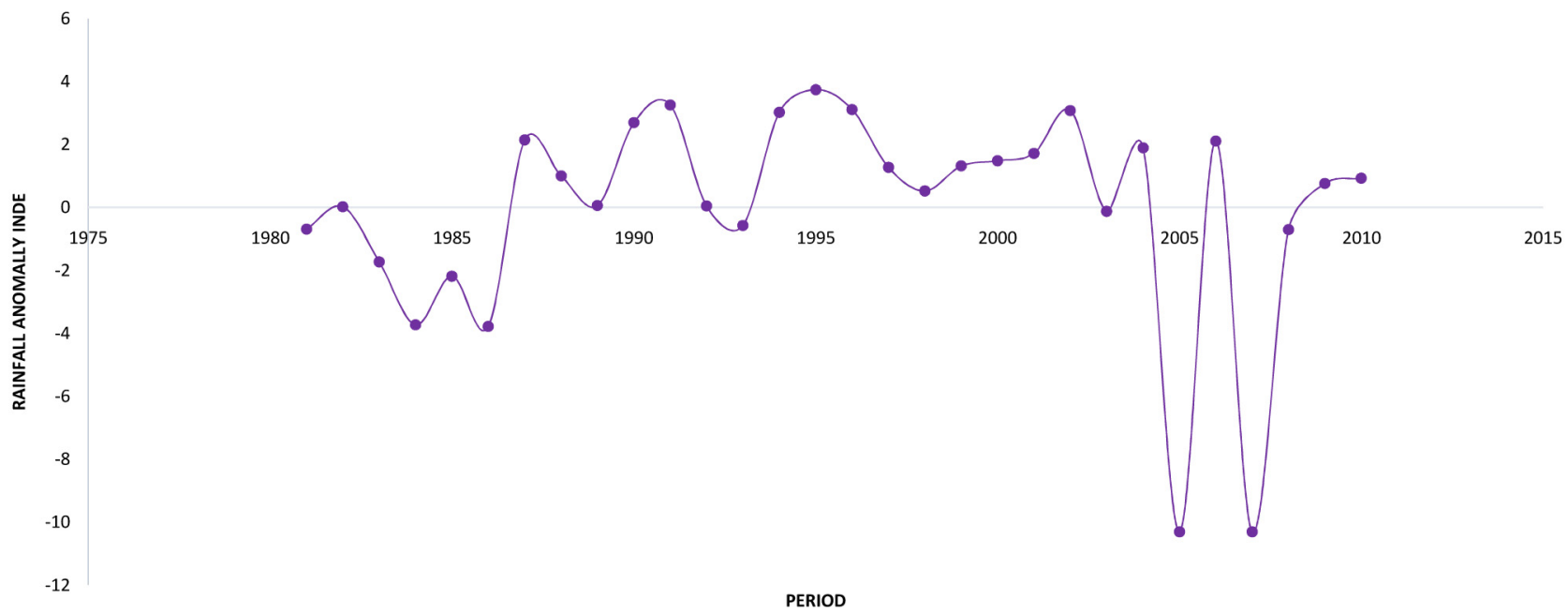

Figure 15. Rainfall anomalies index for Benin. 


\section{ENUGU}

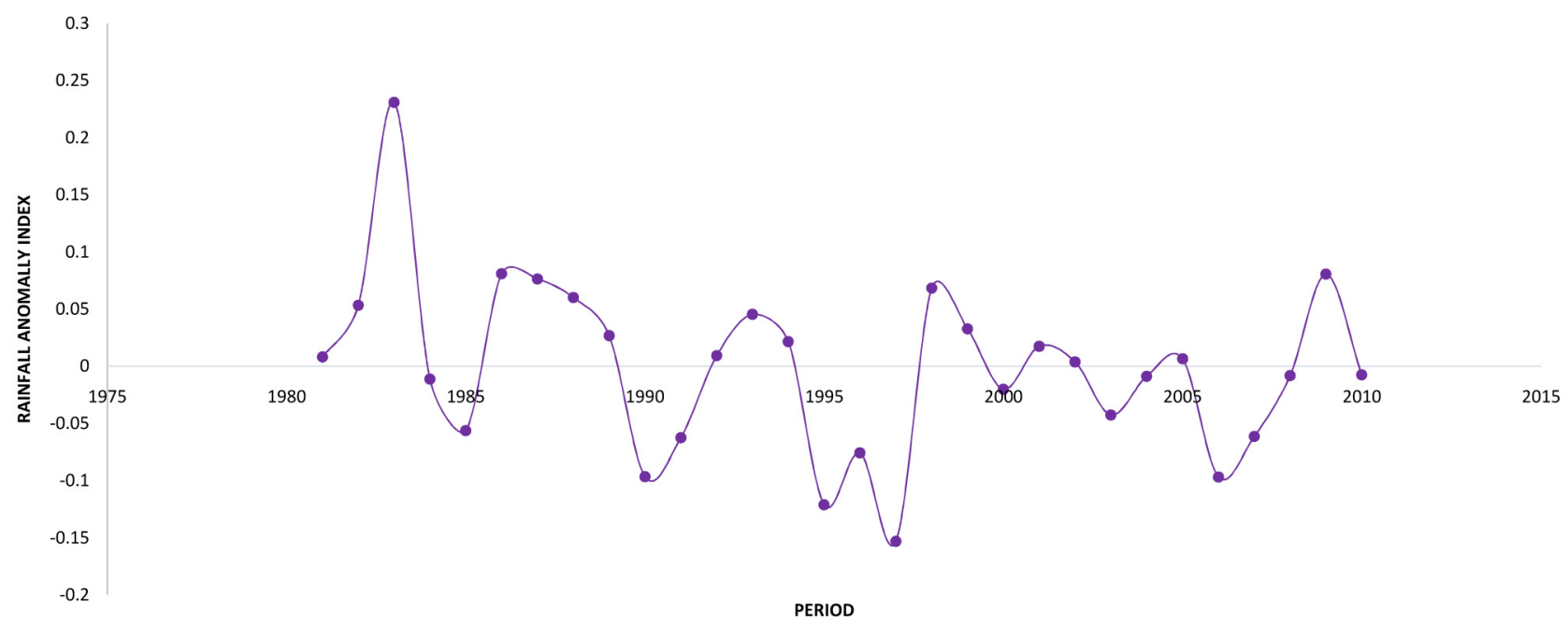

Figure 16. Rainfall anomalies index for Enugu.

The rainfall anomalies index for Lagos in (Figure 17) show that the value ranges from +5.1 in 1997 to -5.8 in 1983 . The value is above the long term mean throughout the period of consideration. There no evidence of drought for the station.

The rainfall anomalies index for Ondo in (Figure 18) show that value ranges from +6.1 in 1991 to -10.0 in 1984 . The value is above the long term mean most of the year. There is no evidence of drought persistence for the station.

The rainfall anomalies index for Ibadan in (Figure 19) show that the value ranges from +5.8 in 2008 to -5.8 in 1983 . The value is above the long term mean throughout the period. There is no evidence of drought for the station.

The rainfall anomalies index for Ilorin in (Figure 20) show that the value ranges from +5.8 in 2008 to -6.7 in 2002. Also the value for Ilorin is above the long term mean throughout the period of consideration. There is no evidence of drought persistence for the station

The rainfall anomalies index for Minna in (Figure 21) show that the value is below the mean value throughout the period of consideration. There is an evidence of drought persistence for the station.

The rainfall anomalies index for Jos in (Figure 22) show that the value ranges from +8.0 in 2003 to -8.2 in 1995 . The value is below the mean value for the early decade from 1980 to 1990 and the value is above the long term mean from 1995 to 2010.

The rainfall anomalies index for Bauchi in (Figure 23) show that the value ranges from +7.0 in 2009 to -5.5 in 1999. The value is below the mean for the early decade and above the long term mean for the past two decades. There is no evidence of drought persistence for the past two decades.

The rainfall anomalies index for Maiduguri in (Figure 24) show that the value ranges from +8.0 in 2007 to -5.1 in 1982. The rainfall clusters together around the mean from 1985 to 1994 , whereas it varies rapidly from the mean around 
LAGOS

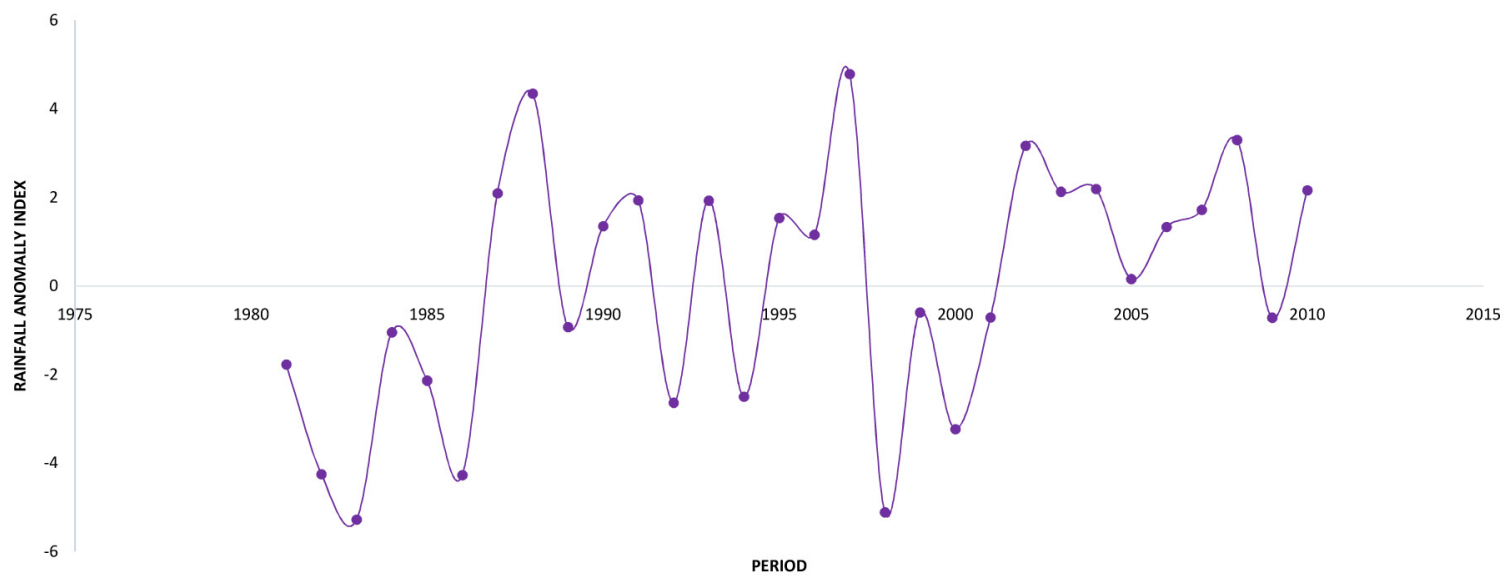

Figure 17. Rainfall anomalies index for Lagos.

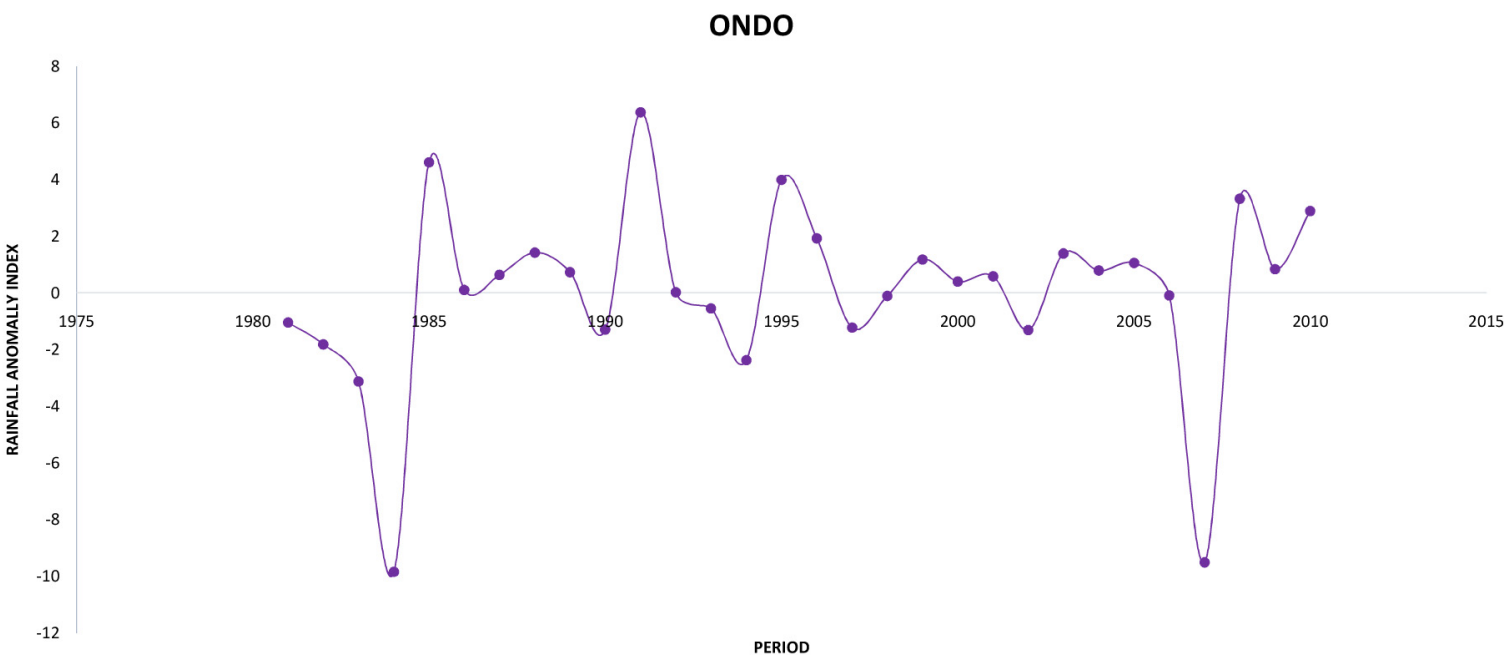

Figure 18. Rainfall anomalies index for Ondo.

IBADAN

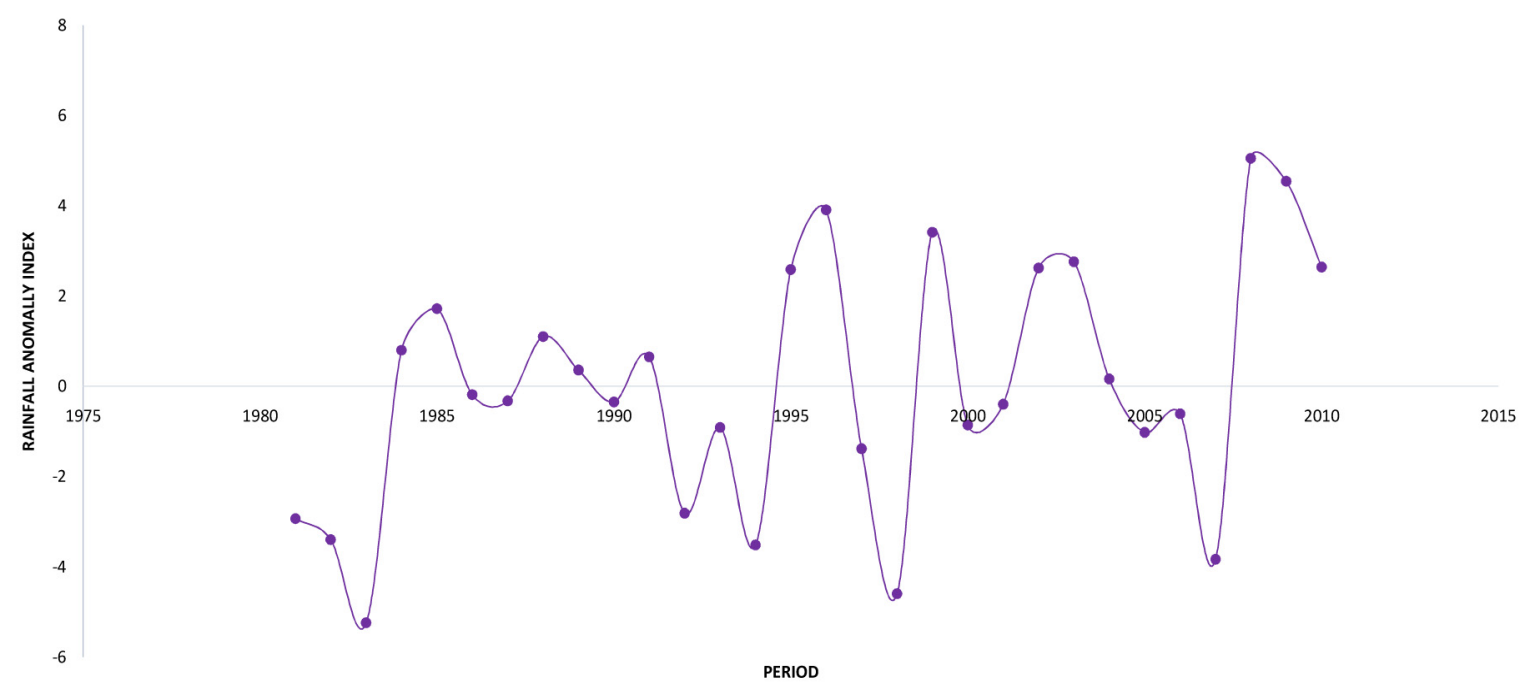

Figure 19. Rainfall anomalies index for Ibadan. 


\section{ILORIN}

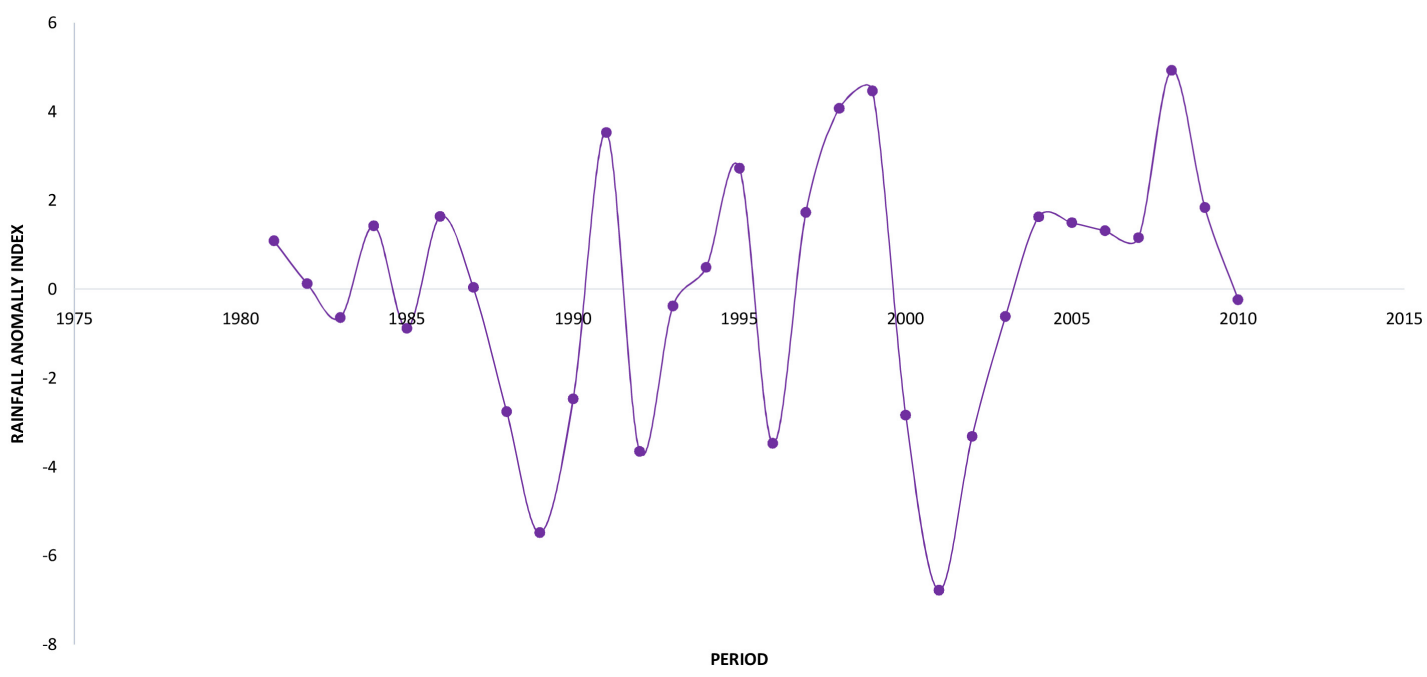

Figure 20. Rainfall anomalies index for Ilorin.

MINNA

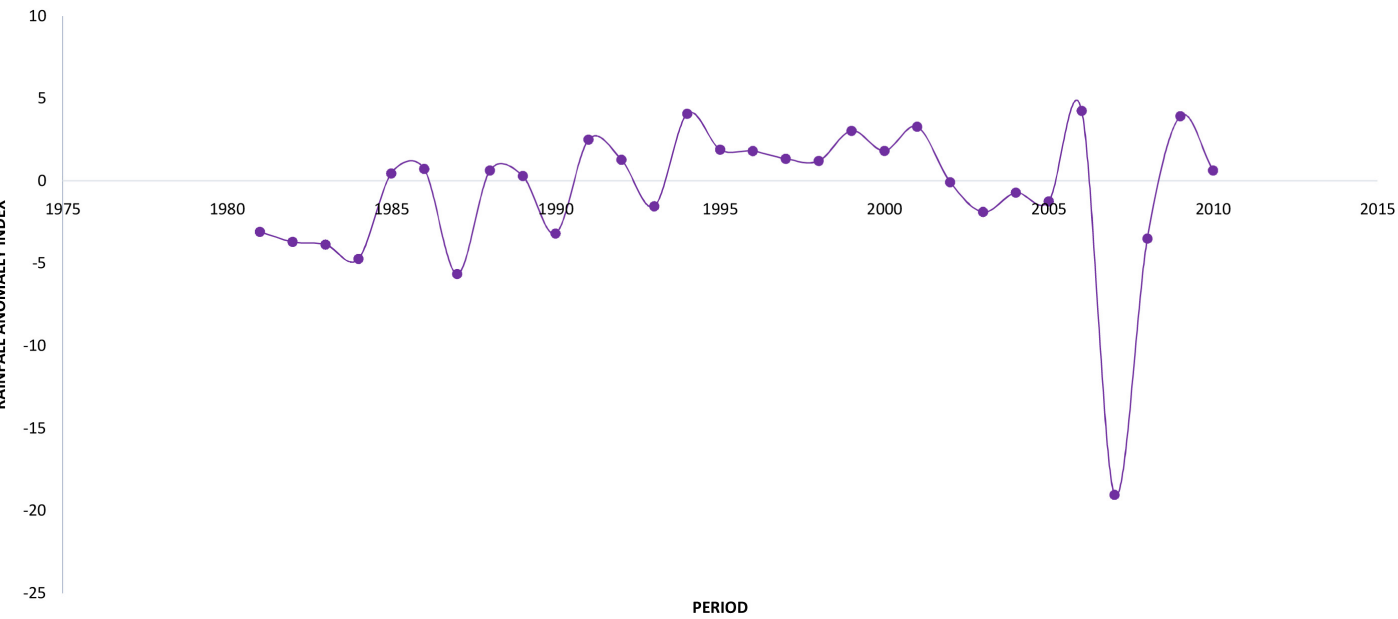

Figure 21. Rainfall anomalies index for Minna.

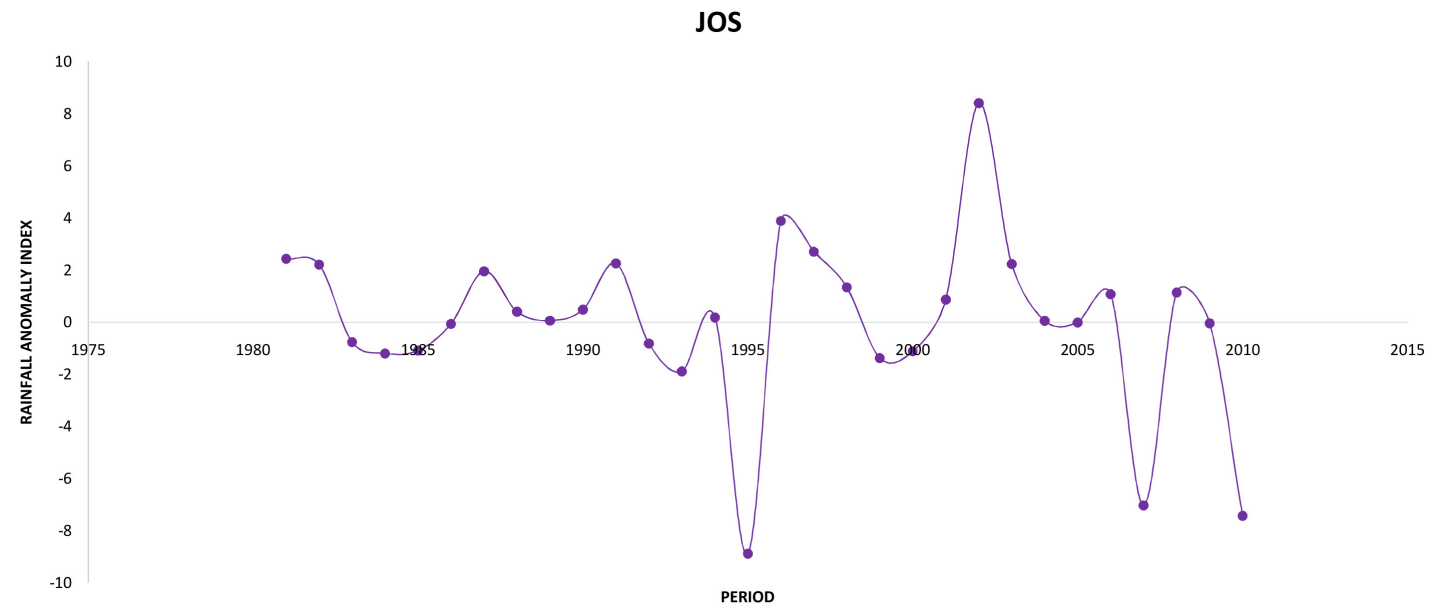

Figure 22. Rainfall anomalies index for Jos. 


\section{BAUCHI}

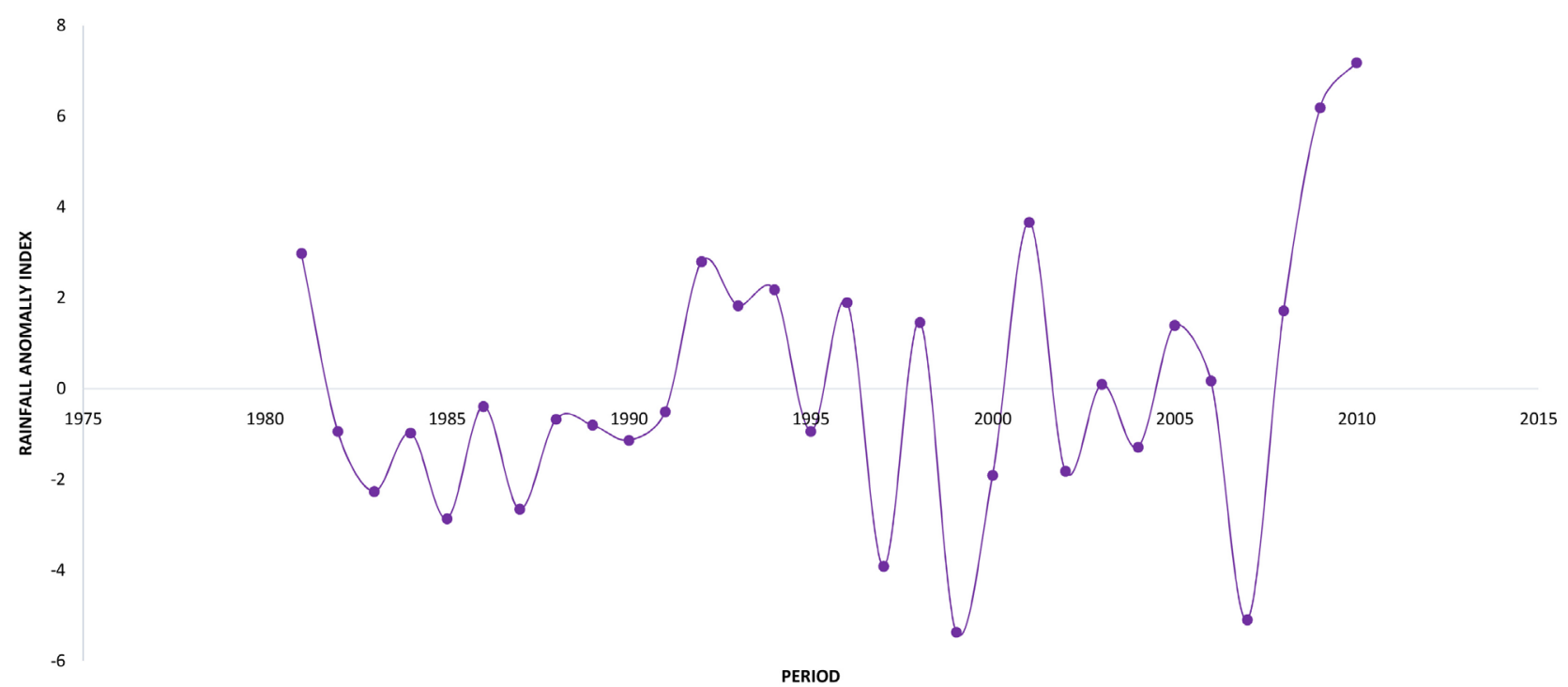

Figure 23. Rainfall anomalies index for Bauchi.

\section{MAIDUGURI}

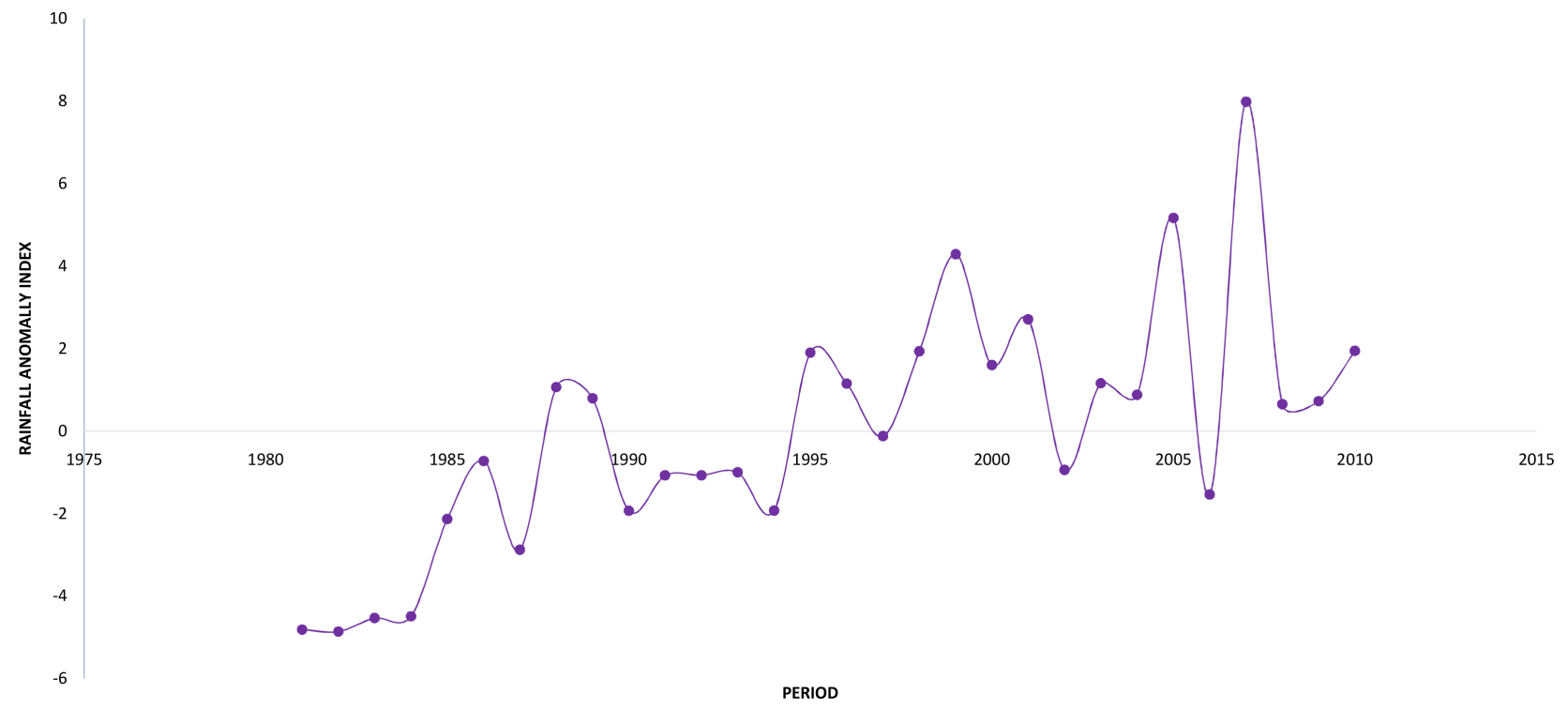

Figure 24. Rainfall anomalies index for Maiduguri.

1995 to 2010. There is no evidence of drought for the past decade.

The rainfall anomalies index for Nguru in (Figure 25) show that the value ranges from +6.0 in 1994 to -8.0 in 2003. The value is below the mean for the early decade and above the long term mean from 1995 to 2000 . There is an evidence of drought for the last decade.

The rainfall anomalies index for Kano in (Figure 26) show that the value ranges from +6.1 in 2001 to -4.1 in 1984 . The rainfall is below the average from 1981 to 1988 . There is an evidence of drought persistence for the station.

The rainfall anomalies index for Sokoto in (Figure 27) show that the value 


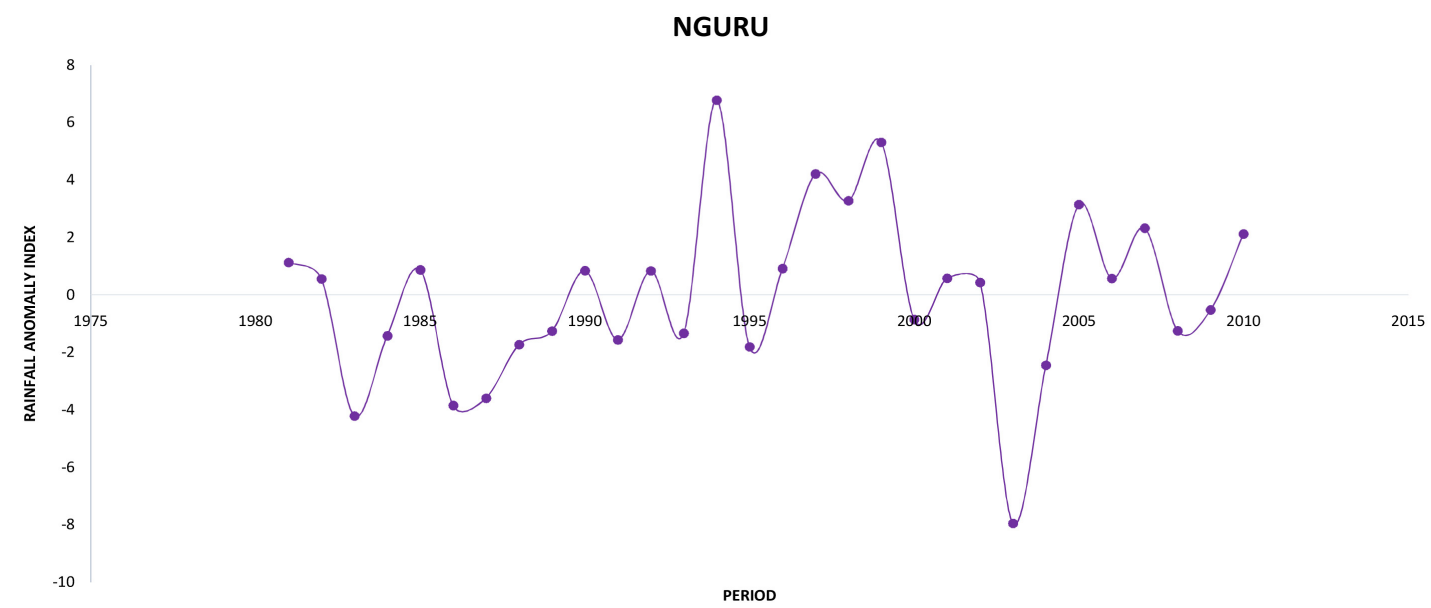

Figure 25. Rainfall anomalies index for Nguru.

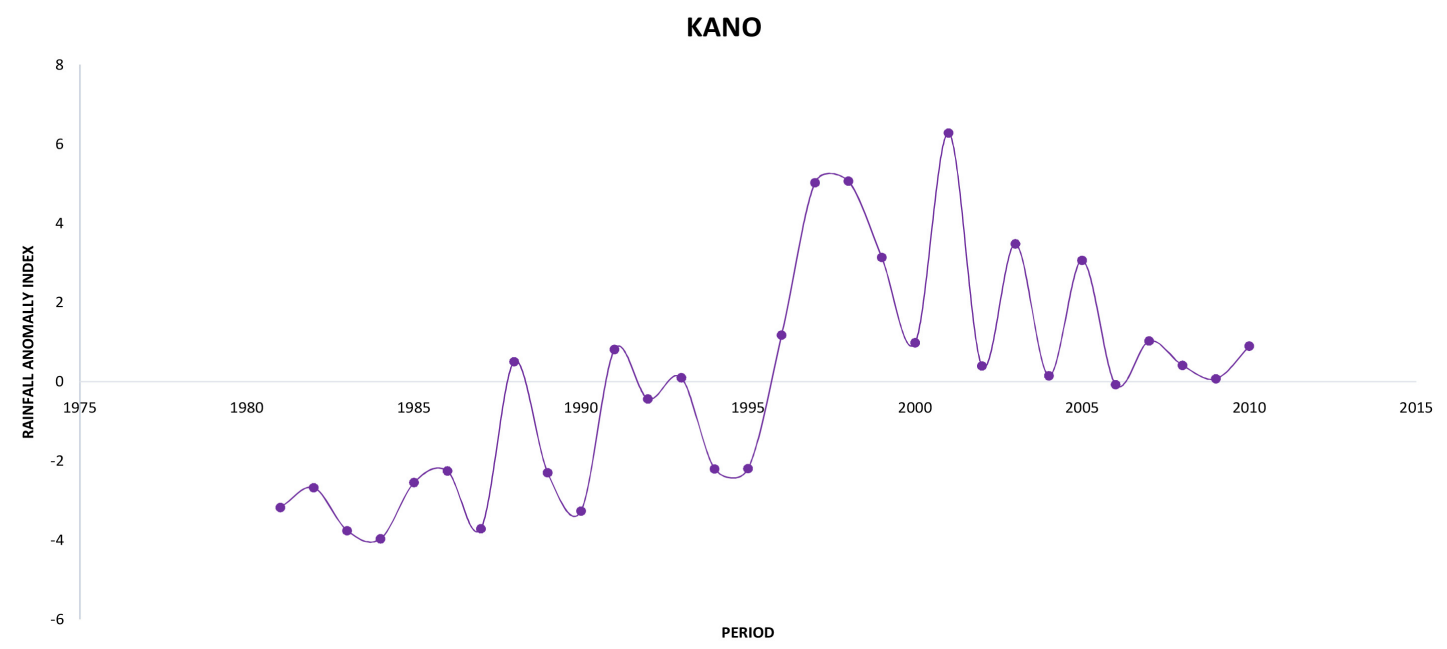

Figure 26. Rainfall anomalies for Kano.

\section{SOKото}

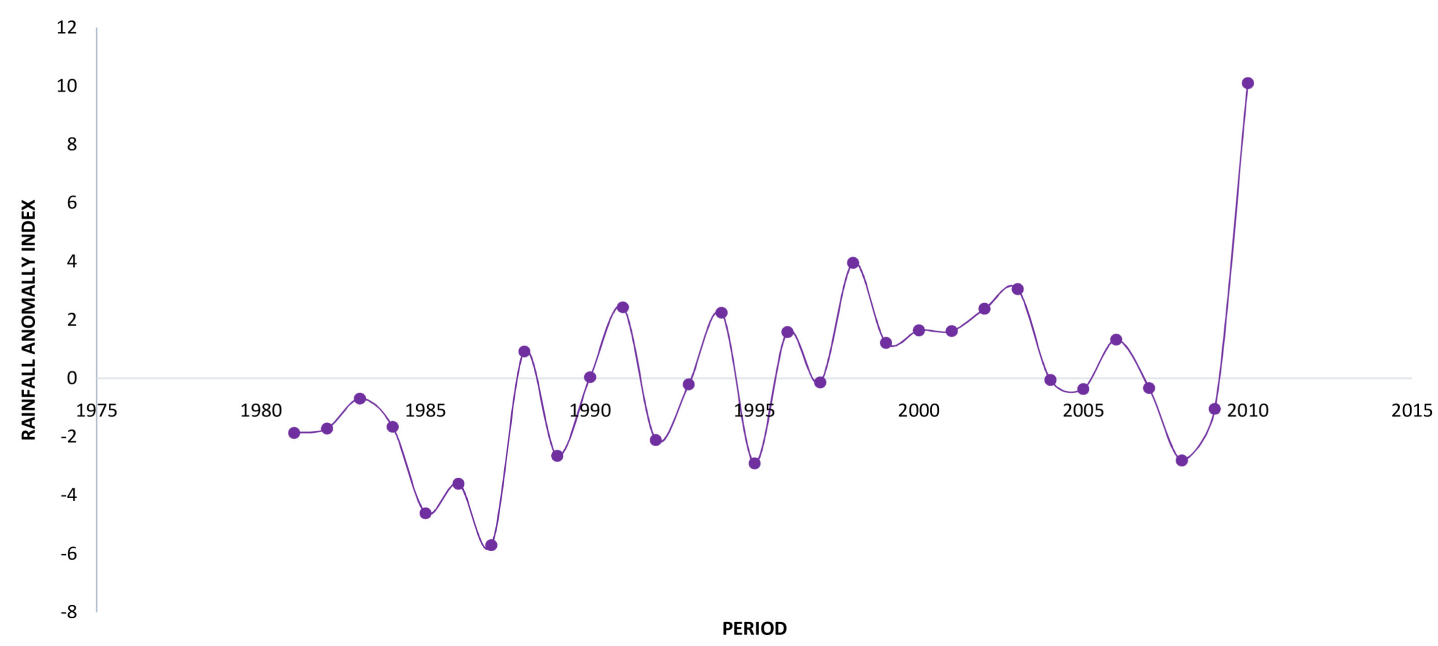

Figure 27. Rainfall anomalies index for Sokoto. 


\section{KATSINA}

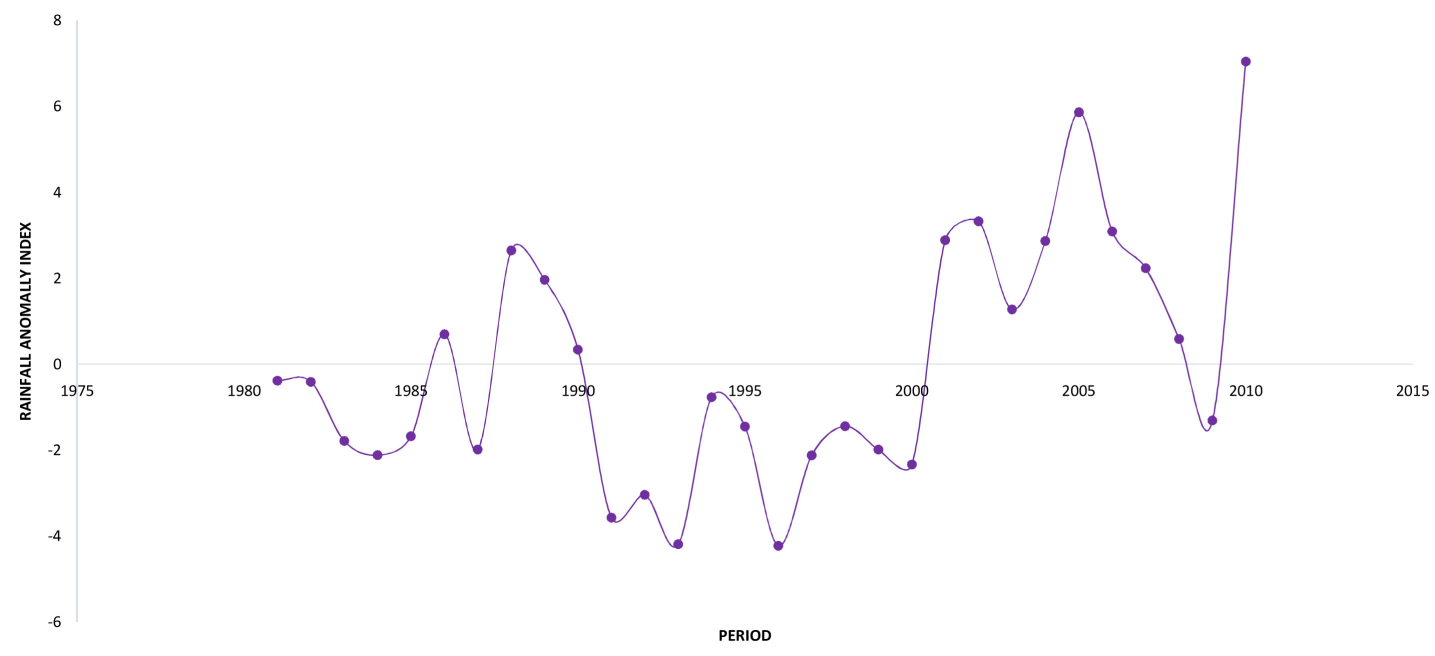

Figure 28. Rainfall anomalies index for Katsina.

ranges from +10 in 2010 to -6.1 in 1987 . The value is below the mean value throughout the period of consideration. There is an evidence of drought for the station.

The rainfall anomalies index for Katsina in (Figure 28) show that the value ranges from +6.1 in 2010to -4.1 in 1996. The value is below the mean value for the earlier two decades and little above the long term mean for the last decade.

\section{Conclusions}

In the analysis carried out in this study, it was observed that temperature trends were not consistent between seasons, in which there is a non-uniform pattern of changes in temperature been evident across the different stations considered. For example, there was an increase of $0.36^{\circ} \mathrm{C} /$ decade in the mean annual temperature for Enugu over the 30 years period. However, Port-Harcourt had the highest positive trend for the rainy season, with Minna having the highest negative trend. Also, Katsina has the highest positive trend and Ilorin the highest negative trend for dry season.

February and March were observed to be the month of highest temperature trend for most of the stations considered, except for Bauchi, Sokoto and Kano with temperature peaking in April. However, Maiduguri, Nguru and Katsina have their own highest temperature peak around May.

In the analysis of trends over the whole region, it was also observed that the variations in the local temperature trends were not spatially uniform. Each of the 18 stations considered exhibits unique trends. Out of the 18 stations considered for seasonal trend, eight (8) of the stations have their rainy season increasing (positive). Also, on a general base, out of the 18 stations considered, 12 of the stations (Calabar, Port-Harcourt, Owerri, Benin, Enugu, Lagos, Ondo, Ibadan, Ilorin, Maiduguri, Sokoto and Katsina) which are mainly stations in the southern part of the country have their mean monthly temperature increasing (posi- 
tive). This shows that majority of the stations in the country are experiencing warming.

The obtained rainfall anomaly index for the plotted rainfall data shows that there is evidence of drought for some of the stations considered (Warri, Benin, Enugu, Minna, Nguru, Sokoto and Katsina), despite that most stations show greater deviation from their mean value throughout the period of consideration in this work. Hence, it is important to continually analyze temperature trend, and check for anomalies in rainfall in order to be able to ascertain good agricultural planning for enhanced economic growth of a nation since all the stations considered have their own peculiar trends that vary from time to time, which are also non-consistent with each other.

\section{Acknowledgements}

We will like to thank NIMET for making available the data utilised in this work.

\section{Conflicts of Interest}

The authors declare no conflicts of interest regarding the publication of this paper.

\section{References}

[1] Nebedum, E.E. and Nnaemeka, V.E. (2016) Climate Change and Its Impact in Nigerian Economy. Journal of Scientific Research \& Reports, 10, 1-13. https://doi.org/10.9734/ISRR/2016/25162

[2] Godwin, A. (2015) Agricultural Vulnerability to Climate Change in Sokoto State Nigeria. African Journal of Food, Agriculture, Nutrition and Development, 15, 9855-9971.

[3] Adger, W.N., Huq, S., Brown, K., Conway, F. and Hulme, M. (2003) Adaptation to Climate Change in the Developing World. Progress in Development Studies, 3, 179-195. https://doi.org/10.1191/1464993403ps060oa

[4] Obot, N.I., Chendo, M.A C., Udo, O. and Ewona, I.O. (2010) Evaluation of Rainfall Trends in Nigeria for 30 Years (1987-2007). International Journal of Physical Sciences, 68, 12-16.

[5] Joshua, J.K. and Ekwe, M.C. (2013) Indigenous Mitigation and Adaptation Strategy to Drought and Environmental Changes in Nigerian Section of Lake Chard Basin. International Journal of Applied Research and Studies (iJARS), 2, 2278-9480.

[6] IPCC (2007) Climate Change and World Food Security: A New Assessment. Global Environmental Change, 9, S51-S67. https://doi.org/10.1016/S0959-3780(99)00018-7

[7] Kruger, A.C. and Shingle, S. (2004) Temperature Trends in South Africa: 1960-2003. International Journal of Climatology, 24, 1929-1945.

https://doi.org/10.1002/joc.1096

[8] Milambo, F.T., Jane, M.O. and Francois, A.E. (2011) Analysis of Temperature Trends over Limpopo Province, South Africa. Journal of Geography and Geology, 3, 1-3. https://doi.org/10.5539/jgg.v3n1p13

[9] Van Rooy, M.P. (1965) A Rainfall Anomaly Index Independent of Time and Space. NOTOS. Weather Bureau of South Africa, 14, 43-48. 
[10] Tilahun, K. (2005) Analysis of Rainfall Climate and Evapo-Transpiration in Arid and Semi-Arid Regions of Ethiopia Using Data over the Last Half a Century. Journal of Arid Environments, 64, 474-487.

https://doi.org/10.1016/j.jaridenv.2005.06.013 